\title{
CHAUPISAWAKASI Y LA EXPANSIÓN PUKARA EN EL VALLE DE QUILCAMAYO-TINTIRI
}

\author{
CHAUPISAWAKASI AND THE PUKARA EXPANSION \\ IN THE QUILCAMAYO-TINTIRI VALLEY
}

\author{
Henry Tantaleán ${ }^{1,2}$ y Carlos Zapata Benites ${ }^{3}$
}

\begin{abstract}
En este artículo se discuten las principales evidencias arqueológicas recuperadas durante nuestras excavaciones en el sitio arqueológico de Chaupisawakasi, ubicado en el valle del río Quilcamayo-Tintiri, departamento de Puno, Perú. Este valle forma parte de la cuenca norte del lago Titicaca. Según nuestras investigaciones, el sitio fue construido por grupos sociales vinculados a la sociedad Pukara (500 a.C.-400 d.C.) y correspondería a un centro político-ceremonial con un sector monumental en el que se realizaron varias prácticas sociales relacionadas con la cultura material clásica de la sociedad Pukara durante el siglo I a.C. Luego de establecer la relevancia que tuvo este sitio dentro del paisaje social del valle del Quilcamayo-Tintiri se realiza una discusión acerca de las estrategias de expansión Pukara en este valle y sus implicancias en otras áreas de la cuenca norte del Titicaca durante el periodo Formativo Superior.
\end{abstract}

Palabras claves: cuenca norte del Titicaca, Pukara, Qaluyu, centros político-ceremoniales, élites.

This paper discusses the main archaeological evidences recovered during excavations at the archaeological site of Chaupisawakasi, located in the Quilcamayo-Tintiri River Valley, Department of Puno, Peru. This valley is located in the northern part of the Titicaca Basin. Our research indicates that the site was built by social groups associated with the Pukara society (ca. 500 BC-AD 400). We conclude that Chaupisawakasi is a Pukara-affiliated political and ceremonial center characterized by a monumental sector that dates to at least the 1st century BC. In this paper, we discuss Pukara expansionary strategies in this valley and we review the implications of this data for other areas of the northern Titicaca region during the Upper Formative Period.

Key words: Northern Titicaca basin, Pukara, Qaluyu, political-Ceremonial center, elites.

Dentro de la investigación arqueológica en los Andes que en la actualidad corresponden al Perú, la cuenca norte del Titicaca ha sido poco favorecida. Pese a la existencia de trabajos arqueológicos esporádicos en el siglo pasado, solamente en los últimos 25 años se han comenzado a generar programas de investigación arqueológica con metodologías de recolección de datos de manera sistemática. Por ello, pese a que la "cultura Pukara" (500 a.C.-400 d.C.) fue descubierta científicamente a mediados de la década de 1920 por Luis Valcárcel (1925), aún tenemos varias lagunas de conocimiento acerca de las características y desarrollo de esta sociedad.

De hecho, nuestro conocimiento actual de las características políticas y económicas de la sociedad Pukara está sustentado principalmente en reconocimientos superficiales que han encontrado muchos asentamientos con arquitectura monumental con cerámica y litoescultura de estilo Pukara (Kidder 1943, Mujica 1978, Stanish 2003, Stanish et al. 2014, Plourde y Stanish 2006). Sin embargo, solo se han excavado sistemáticamente en el sitio epónimo (Chávez 1992; Kidder 1943; Klarich 2005a, 2005b, 2009) y unos cuantos sitios más con presencia de materiales Pukara como Qaluyu (Mohr-Chávez 1977:1020) y Huatacoa en el mismo valle de Pukara (Cohen 2010) o Cachichupa en el valle de Huancané-Putina (Plourde 2006; Plourde y Stanish 2006). Pese a ello, en la actualidad existe un consenso en que Pukara fue una sociedad o jefatura compleja (Klarich 2005b; Mujica 1991) y en los últimos años, incluso, se ha postulado que se trató de un Estado (Stanish y Levine 2011).

Nuestra perspectiva desarrollada en este artículo comparte esta última propuesta añadiendo que se trataría de un Estado teocrático andino en el que un grupo de elite controlaría a otros grupos sociales principalmente por medio de la religión (Tantaleán 2009). La base para la formación de este Estado se hunde en el periodo Formativo, especialmente

\footnotetext{
Cotsen Institute of Archaeology, UCLA Social Sciences Division Department, Los Angeles, USA.

Instituto Francés de Estudios Andinos. Jirón Batalla de Junín 314, Lima 04, Perú. henrytantalean@ yahoo.es

Programa de Investigaciones Arqueológicas Asiruni-PIARA. Jirón Francisco Vidal 414, Lima 05, Perú. carloszb@live.com
}

Recibido: septiembre 2015. Aceptado: julio 2016.

http://dx.doi.org/10.4067/S0717-73562016005000028. Publicado en línea: 23-agosto-2016. 
ligada a la "cultura Qaluyu” (1500-500 a.C.), una formación económica y política relacionada con la existencia de caseríos, aldeas y asentamientos extensos con arquitectura corporativa dispersos por el altiplano de la cuenca norte del Titicaca (Stanish 2003; Tantaleán 2010a, 2010b). A pesar que no es evidente que exista una fuerte integración política entre estos sitios a escala regional, al parecer algunos de los sitios más extensos con concentraciones de arquitectura corporativa estarían compitiendo por concentrar recursos y seguidores mediante rituales y fiestas (Stanish 2003; Plourde y Stanish 2006). Sin embargo, muy pocos sitios, aparte del sitio epónimo (Mohr-Chávez 1977), conteniendo solamente ocupaciones Qaluyu, han sido excavados sistemáticamente (Plourde 2006; Plourde y Stanish 2006). Muchos de estos sitios tienen una reocupación Pukara (Cohen 2010; Levine 2012, 2013; Mohr-Chávez 1977:1020; Mujica y Wheeler 1981; Stanish 2003; Plourde y Stanish 2006; Tantaleán y Leyva 2011).

Con el objetivo de entender de mejor manera cómo se dieron estos procesos sociales tempranos en la cuenca norte del Titicaca, especialmente en un área donde se habían realizado pocos estudios regionales y sistemáticos, se diseñó y ejecutó el Programa de Investigaciones Arqueológicas Asiruni (PIARA) (Figura 1). En especial, el

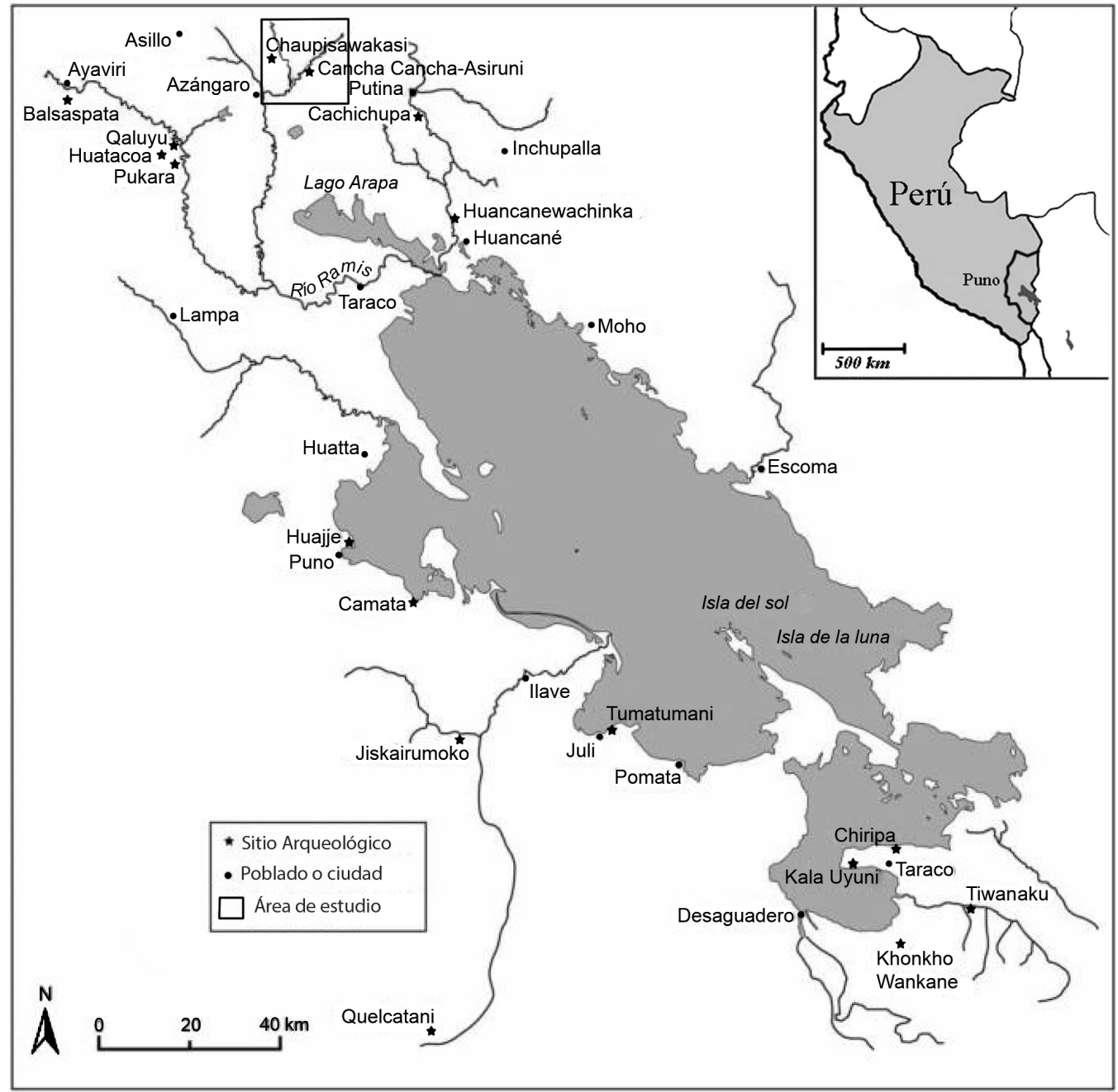

Figura 1. Ubicación del Departamento de Puno, Perú y principales sitios formativos de la cuenca del Titicaca. Se resalta el área de estudio. Modificado de Stanish y Levine 2011.

Location of the Department of Puno, Peru and main formative sites in the Titicaca basin. The study area is highlighted. Modified from Stanish and Levine 2011. 
PIARA se enfocó en la explicación arqueológica de los fenómenos relacionados con el origen de las primeras sociedades complejas con arquitectura monumental en la zona asociada con la sociedad conocida en la literatura arqueológica como Pukara (500 a.C.-400 d.C.). Con tal fin, desde el 2007 se investigó en el valle del río Quilcamayo-Tintiri, ubicado en la actual provincia de Azángaro en el departamento de Puno, Perú (Figura 2). Este pequeño valle que atraviesa la desértica y elevada puna fue elegido, entre otras razones, por existir allí un sitio arqueológico descrito por otros investigadores como uno de los principales asentamientos del periodo Formativo: el sitio de Cancha Cancha-Asiruni (Burger et al. 2000; Chávez y Mohr-Chávez 1970; Stanish 2003, Stanish et al. 2005). Tanta era su relevancia en la arqueología de la cuenca norte del Titicaca que este sitio fue interpretado por Stanish (2003:111) como un "Centro Primario Regional" durante el periodo Formativo Medio (1400 a.C.-500 a.C.) y Formativo Superior (500 a.C. -400 d.C.).

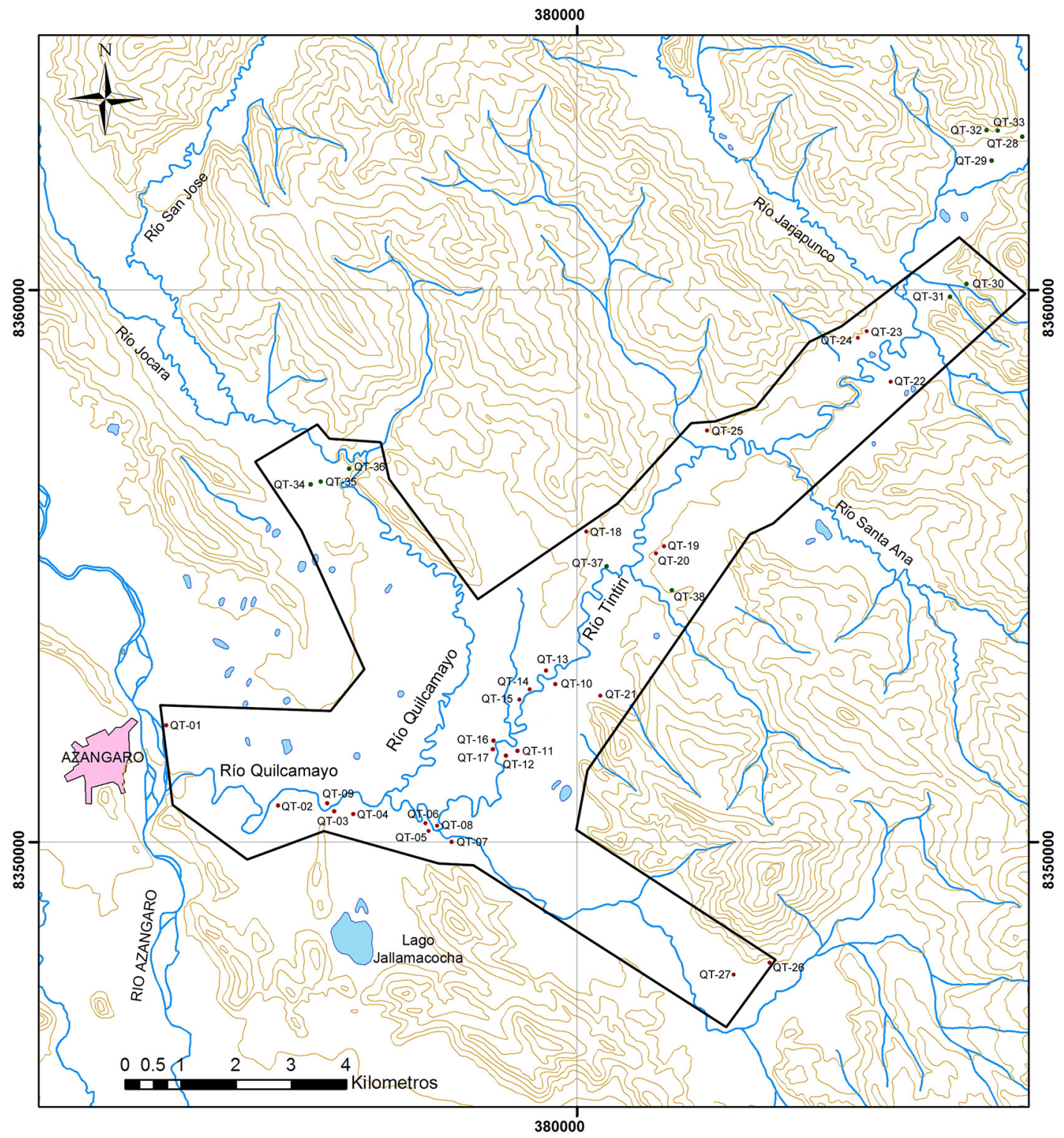

Figura 2. El valle del Quilcamayo-Tintiri y los sitios arqueológicos ubicados por nuestra prospección. Mapa elaborado por Luis Flores Blanco.

Quilcamayo-Tintiri valley and archaeological sites found by our survey. Map elaborated by Luis Flores Blanco. 
Además de la existencia de este importante sitio, elegimos trabajar en este valle por su estrechez y longitud apropiada para poder realizar un reconocimiento total sistemático intensivo y porque no existen centros urbanos modernos que hayan modificado en demasía el paisaje de la zona, así como los mismos sitios arqueológicos. Asimismo, es un valle que no había recibido ningún trabajo sistemático y que estaba relativamente cercano al valle de Pukara donde tenemos al centro urbano prehispánico, del mismo nombre, más importante de la cuenca norte del Titicaca para tiempos del "Formativo Superior" (Kidder 1943; Klarich 2005a, 2005b; Mujica 1991; Stanish 2003).

Siguiendo ese objetivo principal, nuestra investigación en dicho valle ha aportado nuevos datos acerca de una zona no estudiada intensivamente en el pasado. De este modo, se ha incrementado la base de datos acerca de los sitios asociados con el estilo cerámico Qaluyu y Pukara. Por ejemplo, junto con muchos sitios relacionados con el estilo cerámico Qaluyu, hemos reconocido al menos cuatro asentamientos extensos con arquitectura monumental asociados con el estilo cerámico y lítico Pukara (Cancha Cancha-Asiruni, Callacayani, Pancañe y Chaupisawakasi) (Figura 3). Este hallazgo hace más compleja la imagen de las ocupaciones humanas relacionadas con objetos del estilo Pukara más allá del valle del mismo nombre (Tantaleán 2010a, 2010b).

Asimismo, nuestras excavaciones en el sitio de Chaupisawakasi nos brindan la oportunidad de conocer de primera mano la conformación de arquitectura monumental relacionada al fenómeno Pukara en el valle del Quilcamayo-Tintiri. En este artículo nos enfocamos en los recientes descubrimientos relacionados con este sitio y sus implicancias para el conocimiento del fenómeno Pukara en este valle, en particular, y en la cuenca norte del Titicaca, en general.

\section{EI Valle del Quilcamayo-Tintiri}

El valle del Quilcamayo-Tintiri se ubica en una altitud que va desde los 3.850 hasta los 3.900 msm (Figura 3). Hemos definido al valle del río Quilcamayo-Tintiri como la reunión de dos ríos principales, los cuales se unen en uno solo poco antes de alcanzar al río principal de la zona: el Azángaro. El río más largo de este valle es el Tintiri, el cual se origina en las alturas de la cordillera oriental y desciende de noreste a suroeste. Se une con el río Quilcamayo a la altura de la localidad de Pancañe, cercano al poblado de Primero Choquechambi. Por su parte, el río Quilcamayo se origina por la confluencia del río San José y el río estacional Carcapunco a la altura del sitio de Chaupisawakasi.

Ambos ríos presentan un recorrido bastante sinuoso. Presentan escurrimiento superficial entre enero y mayo, teniendo un período de sequía entre junio y septiembre, y alcanzando sus mayores caudales entre enero a marzo. El régimen de descarga que lo caracteriza es torrentoso e irregular, lo que la mayoría de las veces crea problemas a los agricultores que hacen uso de sus aguas.

Los ríos Quilcamayo y Tintiri pertenecen a la subcuenca de San José, dentro de la cuenca del río Ramis que, a su vez, forma parte de la hoya hidrográfica del Titicaca. La subcuenca de San José presenta varios recursos hídricos, entre los cuales se encuentran manantiales, quebradas, ríos, bofedales y lagunas, de estos los más importantes son los ríos Quilcamayo y Tintiri.

El área que comprende el valle QuilcamayoTintiri se encuentra dentro de la "Pradera" o "Bosque Húmedo Montano" (ONERN 1965:3). Esta formación se extiende desde el lago Titicaca hasta los $4.100 \mathrm{msm}$ y es una zona integrada en su mayoría por pampas con pastos naturales, planicies extensas de pendiente suave, de un clima frío, pero no extremo (ONERN 1965:107).

Pese a que según los datos geográficos, ecológicos y altitudinales el valle del QuilcamayoTintiri aparentemente sería una zona marginal para la vida vegetal, animal e, incluso, humana, el estudio arqueológico indica que, por lo menos, desde el periodo Formativo este valle fue intensamente ocupado y se generó producción de animales y vegetales. Además, aunque no son materia de este artículo, se han registrado sitios con ocupaciones del periodo Intermedio Tardío (1100-1450 d.C.) relacionado con los Collas con extensos asentamientos domésticos en cerros (Arkush 2010), ocupaciones domésticas cercanas a los ríos y cementerios. Asimismo, se han evidenciado restos arqueológicos relacionados con la ocupación Inca de la zona.

\section{Estudios Previos en la Zona}

Uno de los primeros investigadores que hizo referencia explícita a sitios arqueológicos en el valle del Quilcamayo-Tintiri fue John Rowe. Sobre la 


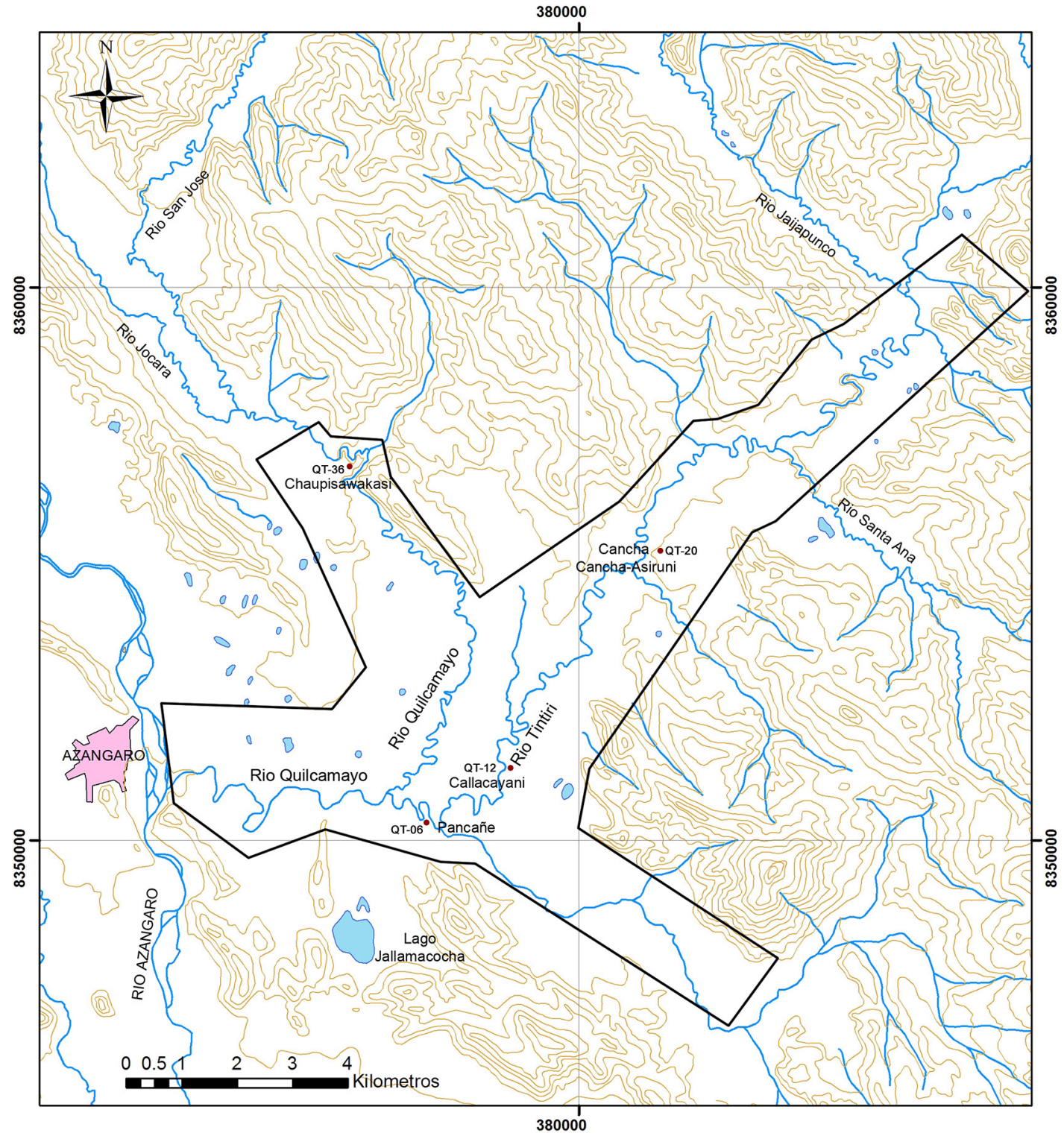

Figura 3. Ubicación de los sitios Pukara del valle Quilcamayo-Tintiri. Se resalta el sitio de Chaupisawakasi. Mapa elaborado por Luis Flores Blanco.

Location of Pukara sites in the Quilcamayo-Tintiri Valley. The Chaupisawakasi site is highlighted. Map elaborated by Luis Flores Blanco.

base de la información proporcionada por Manuel Chávez Ballón, Rowe (1963:7) indicó la existencia de un sitio Pukara en la zona del valle de Tintiri. El sitio identificado por Rowe se trataría del sitio Cancha Cancha-Asiruni (Chávez y Mohr-Chávez 1970:26).

Por su parte, Sergio Chávez y Karen MohrChávez visitaron el valle de Tintiri en 1968. Ellos reportaron la existencia de cuatro monolitos decorados $\mathrm{y}$ tres sin decorar en el sitio de Cancha Cancha-Asiruni (Chávez y Mohr-Chávez 1970:26-31).

Estudios más específicos sobre material recuperado en sitios arqueológicos del QuilcamayoTintiri son los de Burger et al. (2000:312). Ellos señalan con referencia a los artefactos de obsidiana recolectados en el sitio Cancha Cancha-Asiruni que el $75 \%$ procedió de la fuente de Chivay en Arequipa y el 25\% del Tipo Raro 9. Este análisis 
del origen de las fuentes de obsidiana relacionadas con la producción de artefactos asociados a Pukara tiene implicancias con relación al control y/o uso de fuentes de materias primas alejadas de la cuenca del Titicaca. En este caso concreto, estos artefactos serían los más nororientales encontrados hasta el momento relacionados con Pukara, a la vez que asocian a Cancha Cancha-Asiruni a la red de sitios Pukara de la cuenca norte del Titicaca.

Por su parte, Stanish (2003:112) y colegas (Plourde y Stanish 2006; Stanish et al. 2005) han efectuado reconocimientos en la cuenca norte del Titicaca, identificando muchos asentamientos formativos. Sin embargo, para la zona de Azángaro solo señalan al sitio de Cancha Cancha-Asiruni. En este sitio ellos identifican evidencias de ocupación Qaluyu y Pukara y le asignan una extensión de 12 hectáreas, lo que hace del sitio uno de los principales y más extensos para los grupos sociales relacionados con dichas ocupaciones en la cuenca norte del Titicaca.

Finalmente, nuestros reconocimientos han sido, hasta el momento, los estudios más intensivos y sistemáticos en este valle. Los resultados de estas investigaciones, especialmente de los reconocimientos de superficie y excavaciones restringidas, han sido publicados previamente (Tantaleán 2010a, 2010b; Tantaleán y Zapata Benites 2014; Tantaleán et al. 2012). Dichos estudios han logrado acumular información valiosa para comprender la dinámica de las sociedades prehispánicas en esta zona, especialmente del periodo Formativo. Uno de los últimos trabajos que hemos realizado fue la excavación del sitio de Chaupisawakasi que sustentó de mejor manera una serie de hipótesis que veníamos manejando desde hace años.

\section{El Sitio Arqueológico de Chaupisawakasi}

El sitio de Chaupisawakasi fue descubierto en octubre del 2008 durante nuestras prospecciones intensivas en el valle del Quilcamayo-Tintiri. Se decidió excavar aquí, antes que en otros sitios, por su monumentalidad, su gran extensión para el valle (seis hectáreas) y su alta concentración de cerámica de los estilos Qaluyu y Pukara. Asimismo, su ubicación se relaciona íntimamente con las grandes áreas de qochas que se extienden entre la margen oeste del río Quilcamayo y la margen este del río Azángaro. Esta es una de las concentraciones más importantes de esta tecnología hidráulica temprana después de las del río Pukara (Flores Ochoa y Paz 1983; Flores et al. 2012)

El sitio arqueológico de Chaupisawakasi se encuentra ubicado en la margen sur o derecha del río San José, cercano a la confluencia con la quebrada Carcapuncu, punto desde el cual el río se denomina Quilcamayo. Las coordenadas UTM en la parte central del sitio son 19L 0375434 E 8356838 S y se encuentra a $3.889 \mathrm{msm}$. Políticamente corresponde a la comunidad campesina de Chaupi Sahuacasi, que pertenece a la provincia de Azángaro del departamento de Puno (Figura 3).

Este sitio tiene como edificación principal a una gran plataforma delimitada por grandes muros de piedras, visibles sobre todo en el lado norte y que alcanzan los tres metros de altura. Asimismo, el sitio está compuesto por una extensa área de densas acumulaciones de restos arqueológicos y estructuras de piedra que, al parecer, compondrían un sector doméstico relacionado con la plataforma principal (Figura 4).

Sobre la plataforma principal se encuentra un área relativamente llana, en la cual se percibe una depresión cuadrangular de unos 10 metros por lado. Al borde de esa depresión cuadrangular se aprecian grandes bloques de piedra trabajada que parecen haber formado parte de muros, muy similares a otros ejemplos de estructuras asociadas a Pukara, especialmente plazas o patios hundidos. Adicionalmente, al oeste de la plataforma principal se pueden observar otros bloques de piedra que han sido removidos de su lugar original. Las casas actuales también han utilizado muchas de las piedras trabajadas de estructuras arquitectónicas arqueológicas para la construcción de sus muros. En toda la superficie del sitio se encuentra gran cantidad de materiales arqueológicos, especialmente fragmentos de cerámica formativa y tardía (Collao) y desechos de talla lítica. Existe una mayor concentración de material arqueológico en la parte norte del sitio, dado que el río San José ha erosionado este sector (Figura 5).

En esos perfiles se pueden reconocer grandes bloques líticos formando muros, capas de piedras escogidas que hemos visto en otros sitios formativos y que, posiblemente, constituyeron pavimentos; y extensas capas producto de actividad antrópica en la que se reconocen restos cerámicos, óseos, líticos y otros. En general, se puede apreciar que hay una gran ocupación con restos de consumo de artefactos, plantas y animales que parecen de carácter doméstico, aunque también se pueden reconocer eventos de 


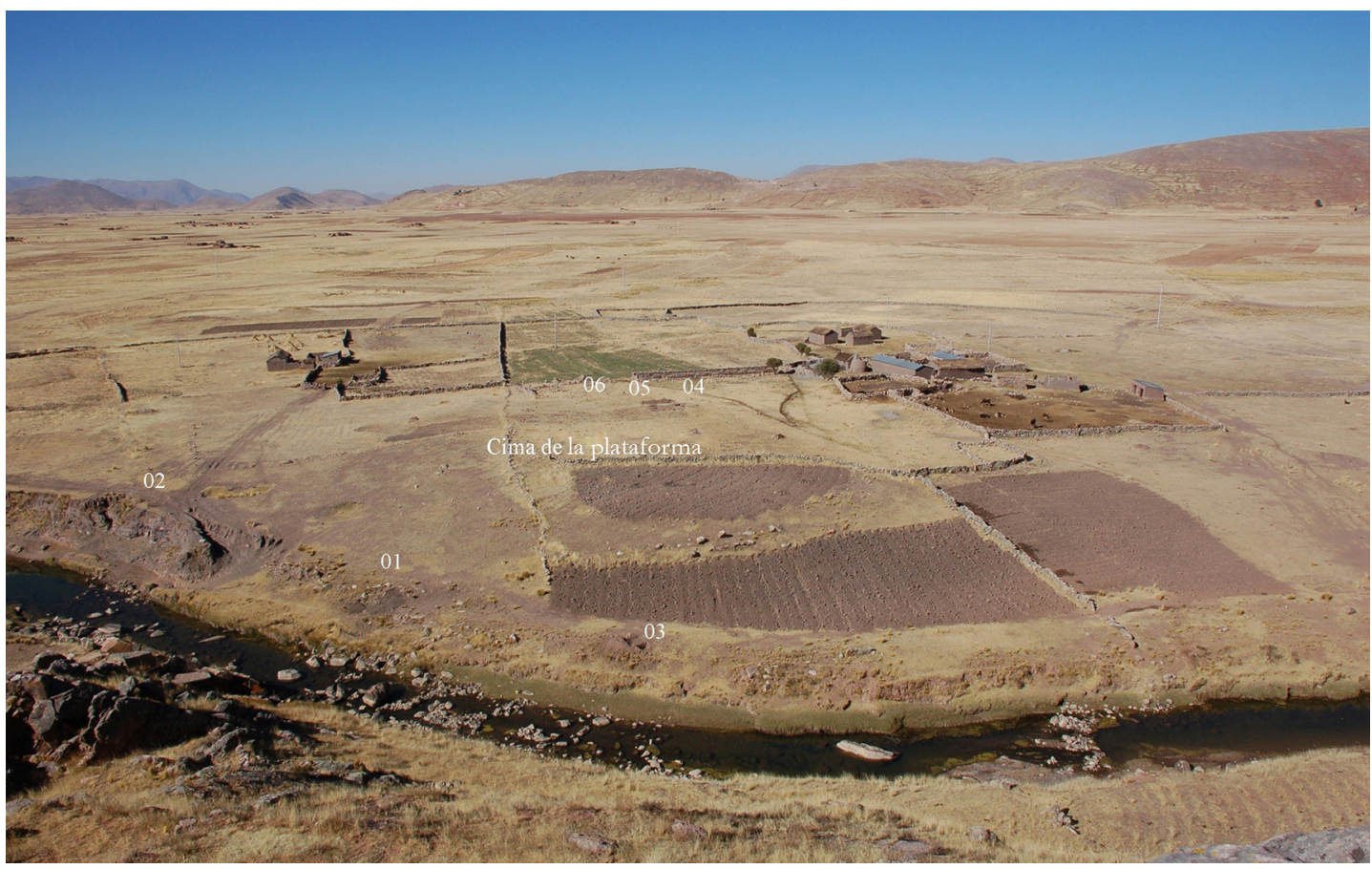

Figura 4. Vista oblicua desde el norte del sector central del sitio de Chaupisawakasi que linda con el río San José. Se señalan las unidades de excavación con sus respectivos números.

Oblique view from the north of the central sector of the Chaupisawakasi site. The San José River is in the lower margin. Excavation units are indicated with their respective numbers.

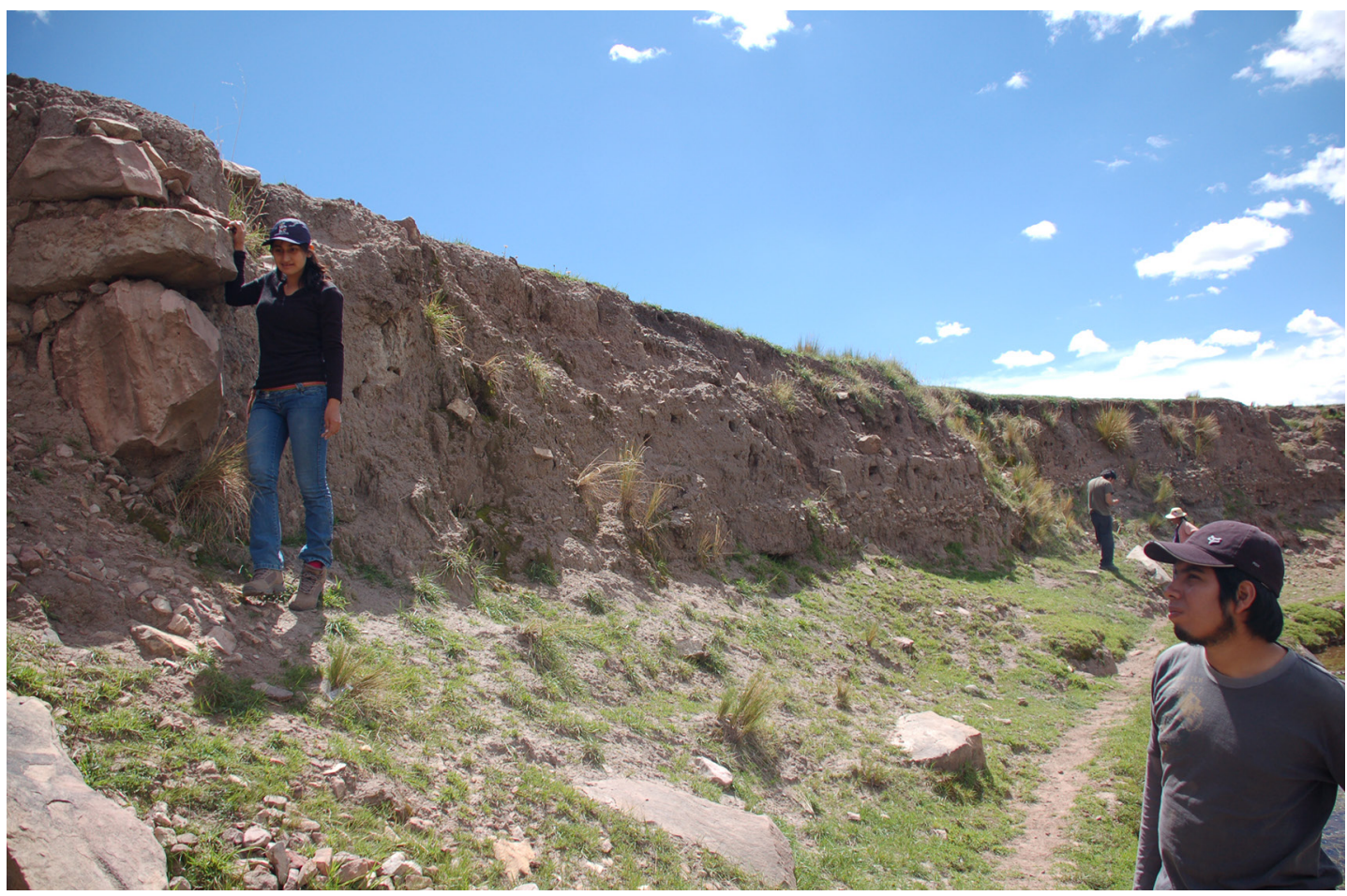

Figura 5. Vista del perfil norte del sitio de Chaupisawakasi.

View of the northern profile of the Chaupisawakasi site. 
construcción de arquitectura monumental asociados a grandes bloques líticos. En general, estas capas están asociadas con cerámica del estilo Qaluyu y Pukara. Asimismo, hemos recolectado puntas líticas que, por su morfología, datarían de la época "Arcaica" o "Precerámica", lo cual nos señala que el sitio pudo haber comenzado a ser ocupado desde esos momentos.

También se han reconocido concentraciones de material arqueológico en la otra banda del río. Más allá de lo anterior descrito, las estructuras arqueológicas no son visibles en superficie. Por tanto, se tornó necesario realizar excavaciones en el sitio para poder definir claramente su antigüedad, ocupaciones humanas y características.

\section{Excavaciones y Materiales Recuperados en Chaupisawakasi}

Nuestras excavaciones en el sitio de Chaupisawakasi se restringieron a cinco pozos de sondeo. De todas las unidades de excavación realizadas, la Unidad 04 ( 2 m x $1 \mathrm{~m})$, abierta en la cima de la plataforma principal, nos ofreció una mayor cantidad de evidencias arqueológicas. A la vez, nos permitió conocer su proceso de construcción y, sobre todo, con qué tipo y estilo de artefactos estuvo relacionada (Figura 6). Asimismo, la excavación de esta unidad permitió establecer una secuencia de niveles ocupacionales (Figura 7) relacionados con estilos cerámicos conocidos, como se aprecia en la Tabla 1.

Las evidencias recuperadas en esta unidad fueron publicadas detalladamente en otro lugar (Tantaleán y Zapata Benites 2014). Por tanto, aquí solo haremos una síntesis de estas evidencias y su respectiva vinculación con las ocupaciones humanas reconocidas.

\section{Cerámica}

En general observamos que existe una mayor diversidad de material cerámico en los tres primeros niveles ocupacionales del sitio. Los tazones están presentes en toda la secuencia arqueológica del sitio, pero tiene su mayor concentración en el $2^{\text {do }}$ y $3^{\text {er }}$ nivel ocupacional del sitio, los cuales están relacionados con Pukara. Asimismo, el único fragmento de incensario que hemos registrado se encuentra en el $3^{\text {er }}$ nivel ocupacional.

Resulta interesante que durante la ocupación vinculada a Qaluyu, la vajilla de servicio utilizada

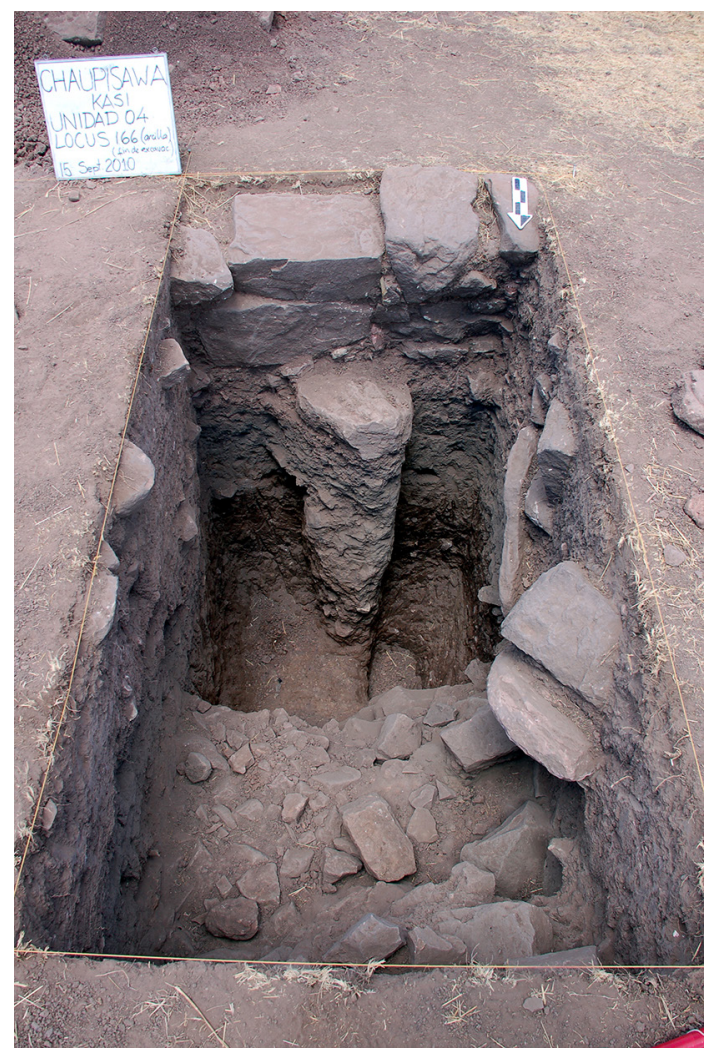

Figura 6. Vista del perfil sur de la Unidad 04. En la parte más superficial se notan las dos hiladas de bloques líticos que forman parte del edificio rectangular en la cima de la plataforma principal. Debajo de estos restos de muro se encuentran varias capas arqueológicas asociadas con diversos materiales como cerámica Pukara Polícroma.

View of the southern profile in Unit 04. On the most superficial part, two rows of lithic blocks are noted that form part of the rectangular building on top of the main platform. Below the remains of this wall, a series of archaeological strata associated with diverse material, like Pukara Polychrome ceramics, were found.

para consumo de alimentos (tazones y cuencos) tenga la misma proporción que la vajilla de cocina (ollas) (Figuras 8, 9 y10). Por otra parte, en los niveles ocupacionales Pukara la vajilla de servicio es superior en porcentaje y las vasijas de almacenaje también aumentan. Esto resulta coherente con lo encontrado en otros sitios Pukara donde la vajilla de consumo (Pukara Polícromo) aumenta en número. Interesantemente, esta relación regresa a magnitudes similares a las de Qaluyu en el $4^{\text {to }}$ nivel ocupacional relacionado con los últimos momentos de ocupación Pukara de la plataforma.

Adicionalmente, nuestro análisis de pastas de la cerámica no pudo determinar la predominancia 


\section{Perfil Este - Unidad 04}
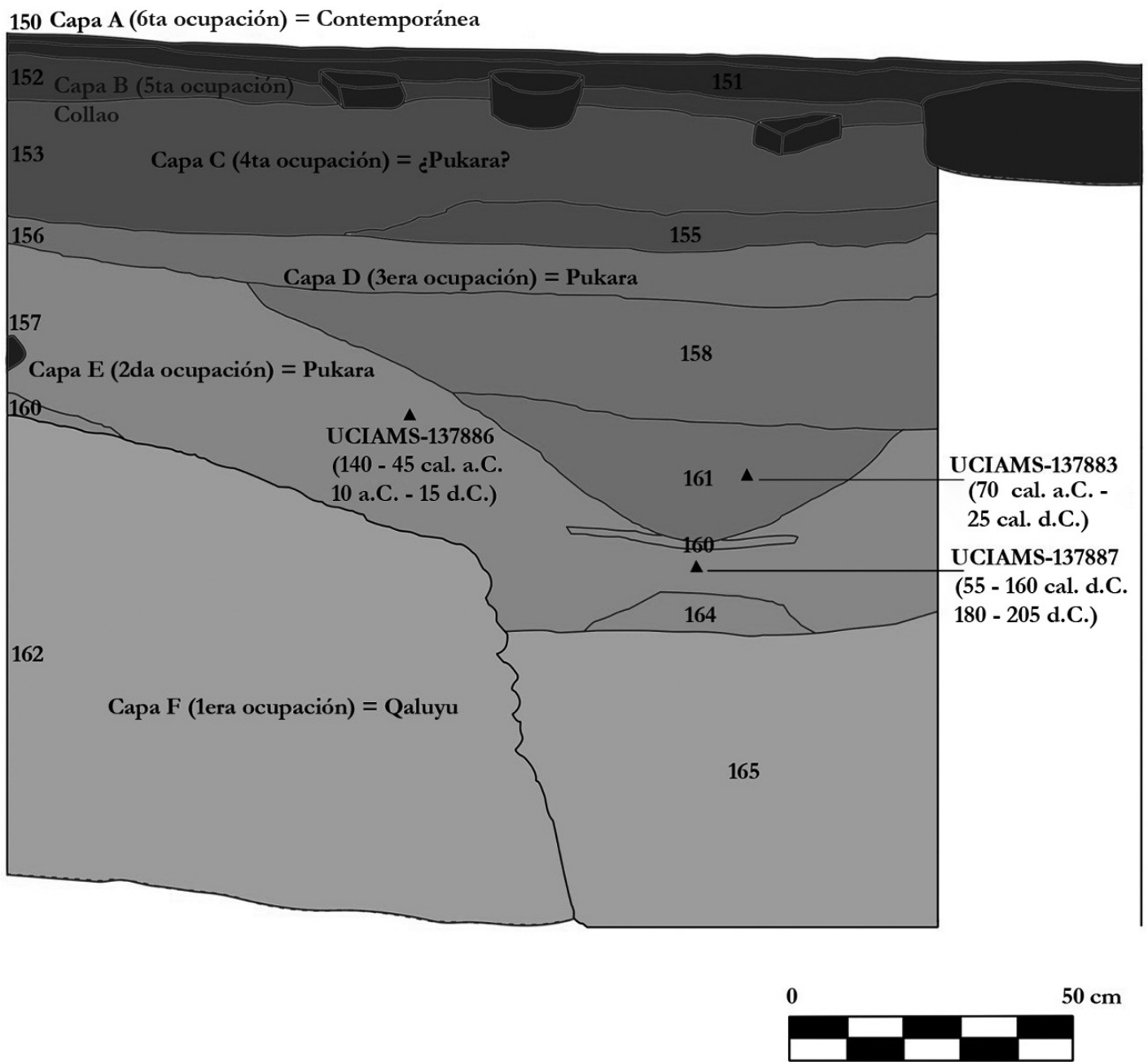

Figura 7. Perfil norte de la Unidad 04 y ubicación de las muestras tomadas para los fechados radiocarbónicos. Northern profile of Unit 04. Locations of samples taken for $\mathrm{C}^{14}$ dating are indicated.

Tabla 1. Correlación entre sociedad/estilo, nivel ocupacional, capa, locus y número de tiestos diagnósticos en la Unidad 04. Correlation among society/style, occupational level, stratum, locus and diagnostic sherds in Unit 04.

\begin{tabular}{ccccc}
\hline Sociedad/Estilo & Nivel ocupacional & Capa & Locus & $N^{\text {o de tiestos }}$ \\
\hline Contemporánea & $6^{\text {to }}$ & A & 150,151 & 6 \\
Collao & $5^{\text {to }}$ & B & 152 & 3 \\
¿Pukara? & $4^{\text {to }}$ & C & $153,154,155$ & 7 \\
Pukara & $3^{\text {er }}$ & D & $156,158,161$ & 29 \\
Pukara & $2^{\text {do }}$ & E & $157,160,163,164$ & 10 \\
Qaluyu & $1^{\text {er }}$ & F & 162,165 & 0 \\
Estéril & Estéril & G & 166 & 0 \\
\hline
\end{tabular}




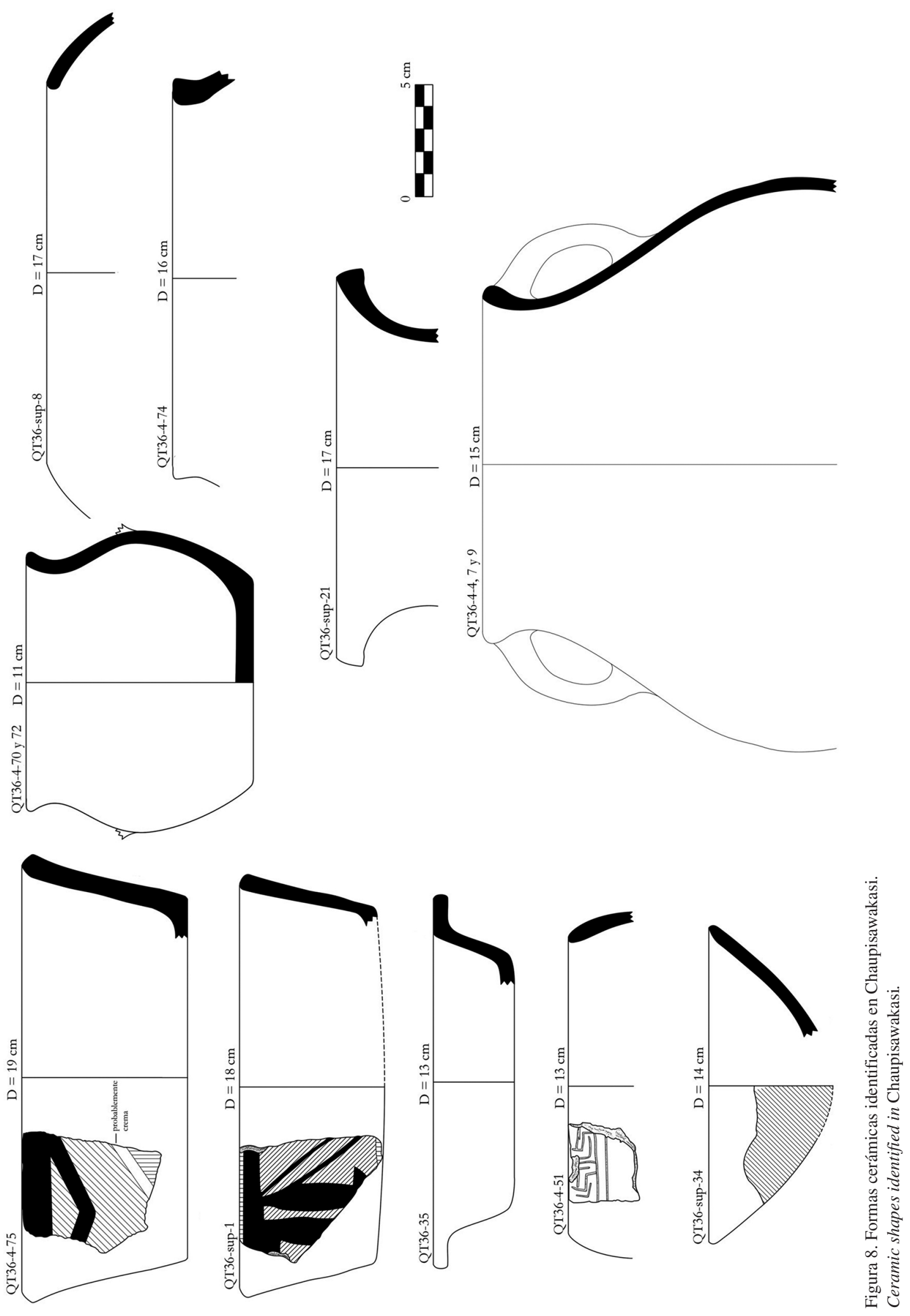




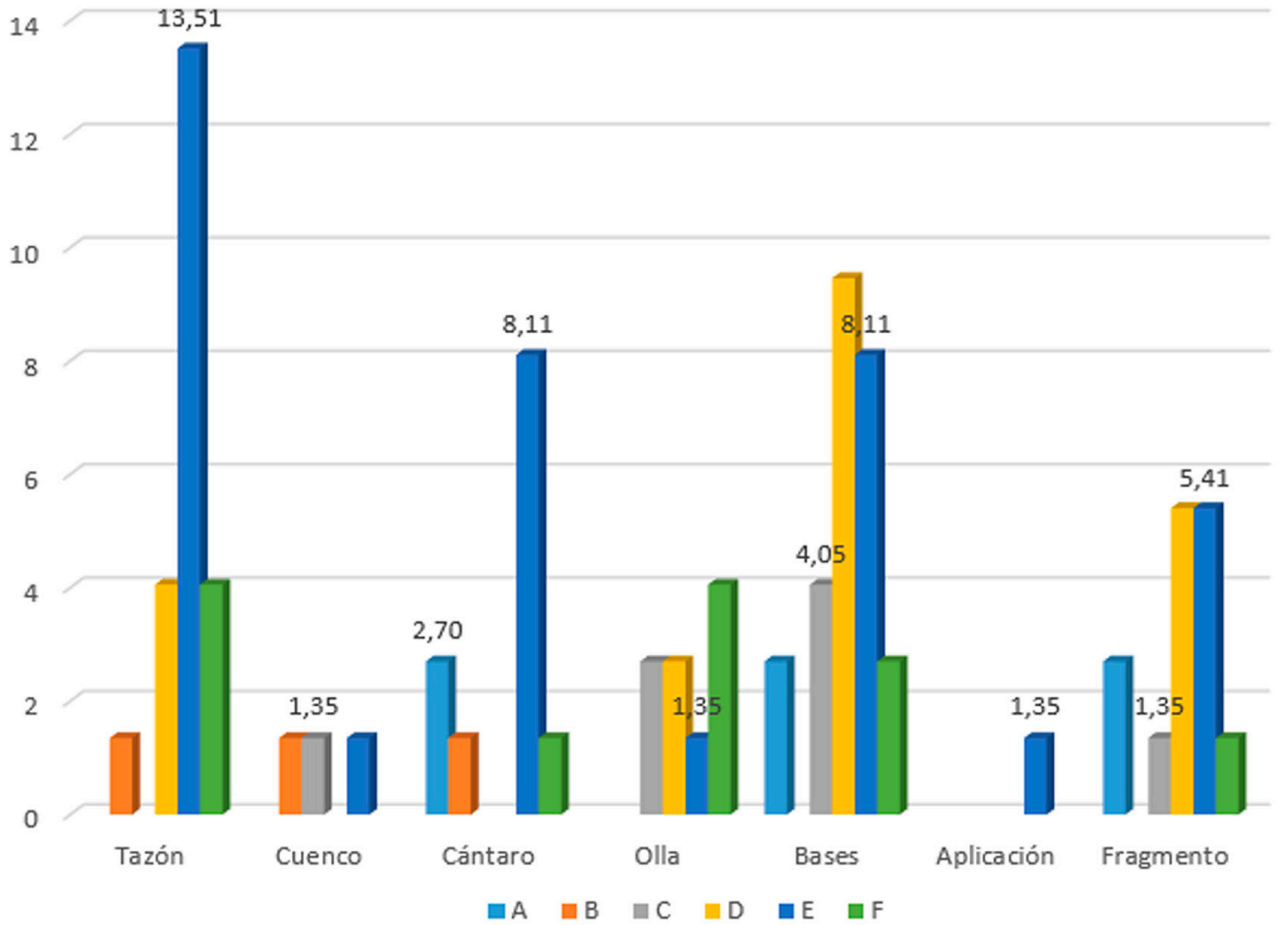

La muestra comprende 74 tiestos.

Figura 9. Porcentaje de formas cerámicas registradas en Chaupisawakasi según las capas identificadas en la Unidad 04. Percentage of recorded ceramic shapes in Chaupisawakasi according to strata identified in Unit 04.

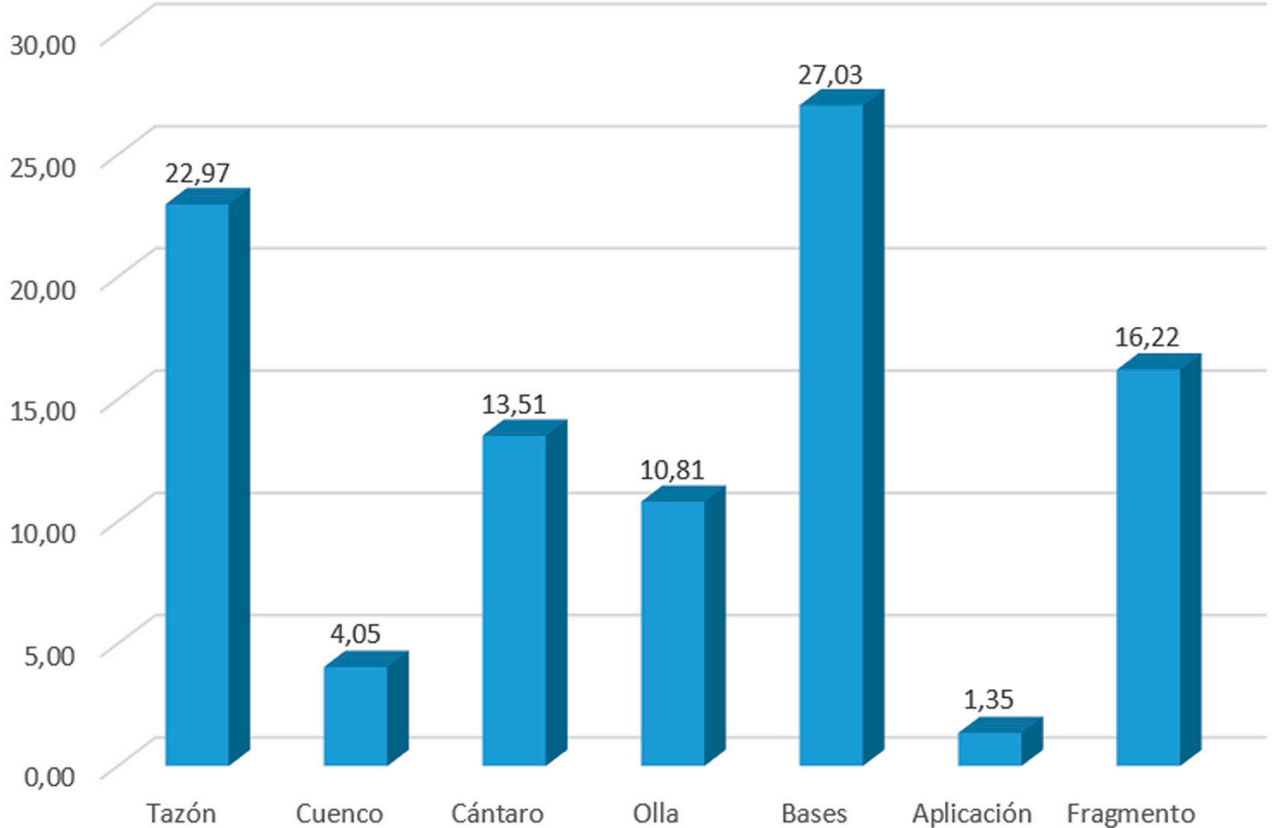

La muestra comprende 74 tiestos.

Figura 10. Porcentaje de formas cerámicas registradas en la Unidad 04.

Percentage of ceramic shapes recorded in Unit 04. 
de algún tipo de pasta (Figura 11). Sin embargo, se puede afirmar que las arcillas utilizadas provienen de por lo menos tres fuentes diferentes. Así, observamos que hay una tendencia al uso de los grupos de pastas III y IV en las ollas, tazones y cuencos. El grupo de pastas III presenta pirita/mica en bajas proporciones y como componente principal al cuarzo o al feldespato; en el caso del grupo IV los antiplásticos se presentan en bajas proporciones y son de menor tamaño.

Asimismo, durante el $1^{\mathrm{er}}$ y $2^{\mathrm{do}}$ nivel ocupacional, las relaciones porcentuales entre los tipos de cocción son similares. Pero son en el $3^{\text {er }}$ y $4^{\text {to }}$ nivel ocupacional que la cerámica de cocción oxidante eleva su porcentaje con relación a otras cocciones. Si tomamos en cuenta que la cerámica de cocción incompleta en la mayoría de casos corresponde a cerámica cocida en atmósfera oxidante, existe una tendencia hacia el uso de la cocción oxidante durante todas las ocupaciones del Formativo y una tendencia a su perfeccionamiento durante los niveles ocupacionales Pukara. Aunque la muestra es reducida, debemos señalar que las vasijas como tazones y cuencos presentan un mayor porcentaje de especímenes de cocción oxidante. Esto podría implicar un mejor control de la cocción del artefacto.

Por otra parte, existe una gran cantidad de cerámica con decoración monocroma. Este dato estadístico se debería en gran medida al tamaño de los fragmentos y al lugar que ocupó la decoración en la vasija. Sin embargo, en todos los niveles ocupacionales, este tipo de decoración es la predominante. En los niveles ocupacionales vinculados solamente con cerámica Qaluyu no se registró la decoración de tipo Polícromo inciso/pintado, bastante relacionada a Pukara. La decoración Qaluyu tipo Polícromo solamente aparece durante los niveles ocupacionales Pukara (Figuras 12 y 13).

Casi todos los fragmentos con decoraciones distintivas de Qaluyu y Pukara, como el Qaluyu Polícromo, el Polícromo inciso/pintado y el Inciso Monocromo presentan pastas del grupo III y grupo IV que, como ya mencionamos, son pastas finas que presentan una inversión de trabajo mayor en la selección o preparación de los antiplásticos. Casi la totalidad de los fragmentos Qaluyu Polícromo y Polícromo inciso/pintado presentan cocción oxidante,

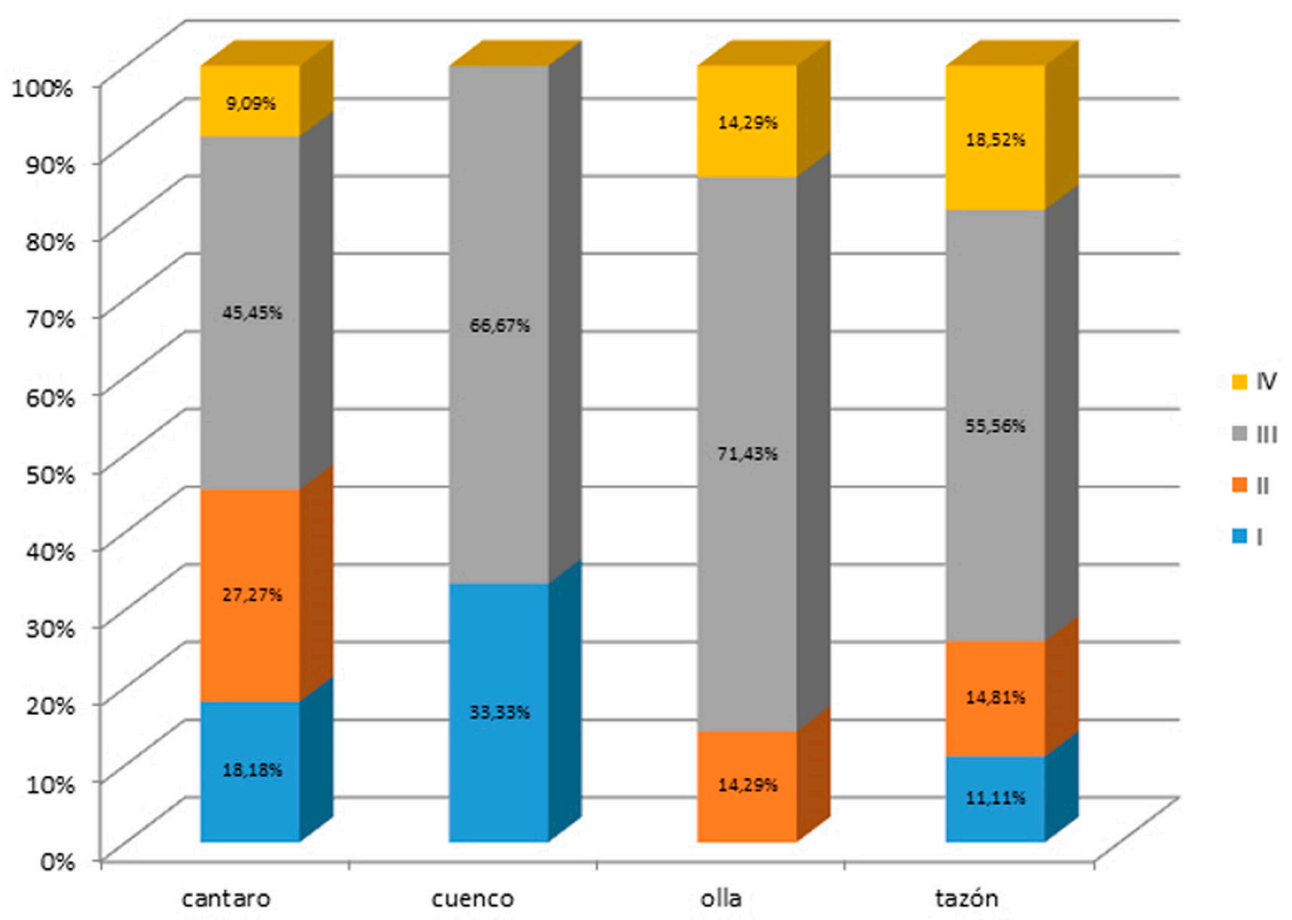

La muestra comprende 48 tiestos que indican forma cerámica.

Figura 11. Distribución porcentual de los grupos de pasta en los totales de cada forma cerámica. Percentages distribution of the paste groups in the totals of each ceramic shape. 


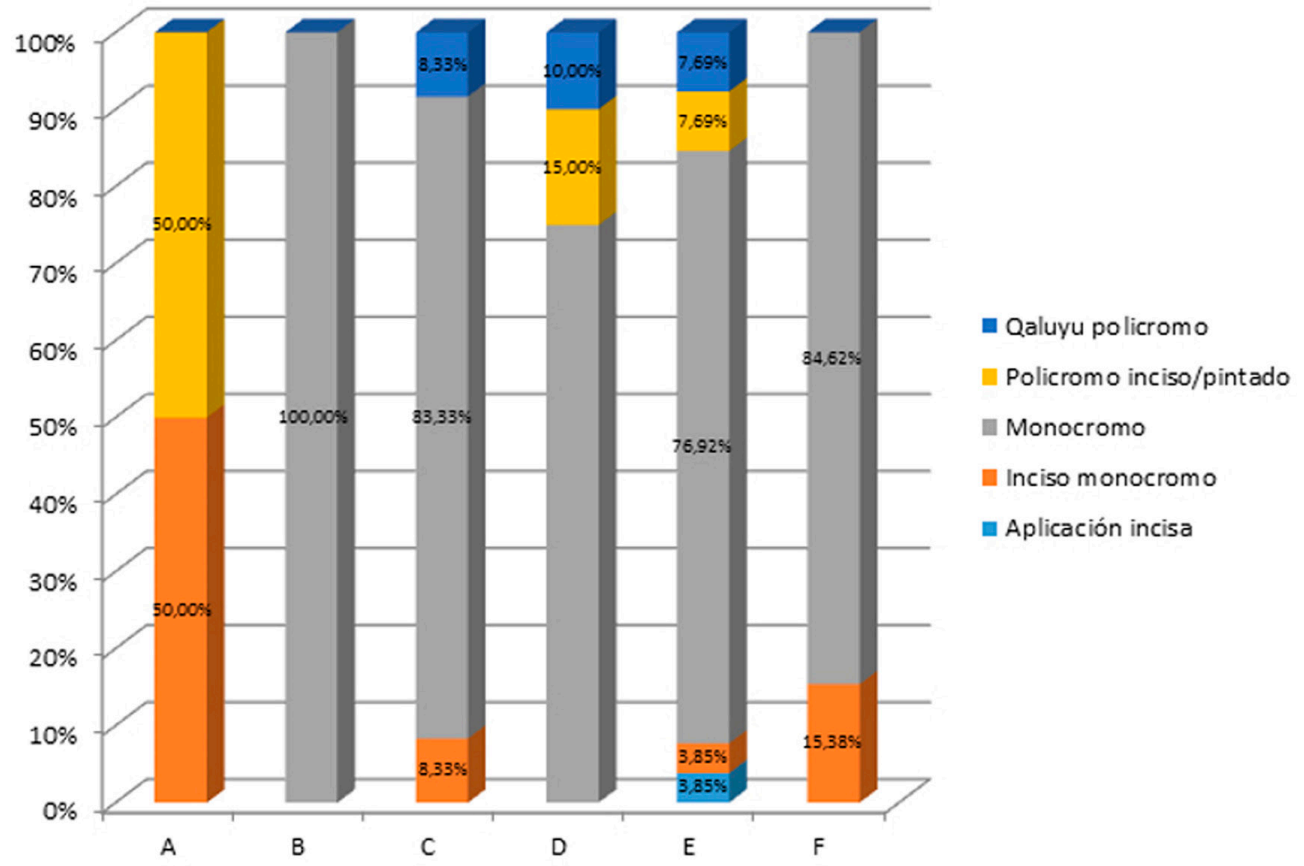

La muestra comprende 74 tiestos.

Figura 12. Distribución porcentual del tipo de decoración en los totales de cada capa de la Unidad 04.

Percentages distribution of the decoration type in the totals of each stratum of Unit 04.

lo que implica una tendencia a una producción especializada de las vasijas decoradas con estos estilos. Las decoraciones Polícromo inciso/pintado y Qaluyu polícromo están hechas todas sobre tazones. Todo esto reafirma la tendencia reconocida en los estilos Qaluyu y Pukara de invertir mayor trabajo en estos artefactos.

Según todas estas evidencias, durante la ocupación Pukara de Chaupisawakasi la producción de las vasijas de cerámica se mejoran tecnológicamente y se invierte materia prima y tiempo para crear vasijas con funciones orientadas a actividades performativas y/o rituales.

\section{Fauna}

Son pocas las especies animales que hemos podido identificar (Tabla 2). Sin embargo, lo importante en la estadística de los restos óseos es el aumento considerable de las cantidades de restos de camélidos en los niveles ocupacionales Pukara ( $2^{\text {do }}$ y $3^{\text {er }}$ nivel ocupacional del sitio). Esto indica un aumento en el consumo de especies animales, especialmente como parte de rituales y/o festines durante la construcción y uso de la plataforma principal. Según Warwick (2012:288, 296), durante las ocupaciones Pukara en el sitio epónimo y en

Tabla 2. Especies animales identificadas.

Identified animal species.

\begin{tabular}{cccc}
\hline Clase & Familia & Especie & NISP \\
\hline \multirow{3}{*}{ Mammalia } & Camelidae & Llama $\mathrm{sp}$. & 315 \\
& Caviidae & Cavia porcellus & 7 \\
& Cervidae & Hippocamelus antisensis & 1 \\
Osteichthyes & Canidae & Canis familiaris & 1 \\
Gasterópoda & N/I & N/I & 2 \\
& Bulimullidae & Scutalus $\mathrm{sp}$. & 5 \\
\hline
\end{tabular}



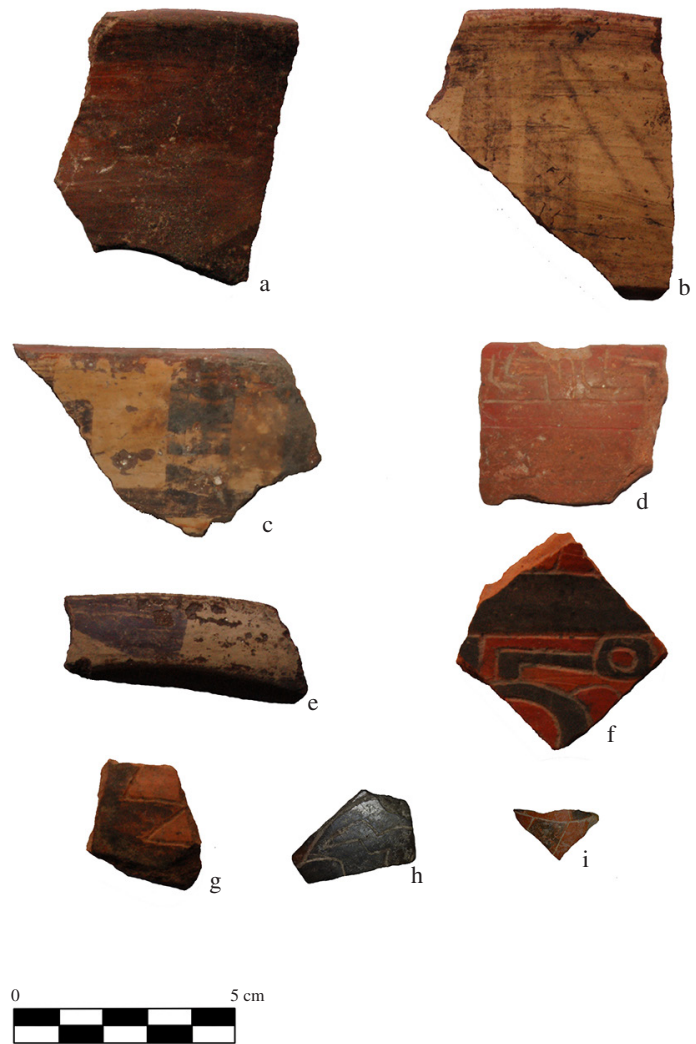

Figura 13. Fragmentos cerámicos decorados destacados recuperados en la Unidad 04. (a) QT36-4-75, (b) QT36-sup-1, (c) QT36-sup-2, (d) QT36-4-51, (e) QT36-sup-3, (f) QT36-4-65, (g) QT36-4-64, (h) QT36-4-60, (i) QT36-4-67.

Featured decorated ceramic sherds recovered in Unit 04. (a) QT36-4-75, (b) QT36-sup-1, (c) QT36-sup-2, (d) QT36-4-51, (e) QT36-sup-3, (f) QT36-4-65, (g) QT36-4-64, (h) QT36-4-60, (i) QT36-4-67.
Huatacoa se dio un incremento del consumo de carne de camélido.

Adicionalmente, los artefactos de hueso identificados que indican una actividad económica especializada, como la textilería, han sido encontrados en los niveles ocupacionales Pukara (Figura 14). Además, en estos niveles se ha evidenciado el uso de ornamentos representados en el hallazgo de cuentas de collares hechas con huesos animales.

\section{Líticos}

Respecto de los niveles ocupacionales Pukara, la cantidad y variedad de los artefactos es superior, con relación a los previos niveles ocupacionales Qaluyu. Lo mismo sucede con los porcentajes de las materias primas exóticas que aparecen en los niveles Pukara (Figura 15).

La variedad de artefactos líticos en el sitio indica su utilización en actividades domésticas, con excepción de las azadas que forman parte de las actividades agrícolas. La producción de estos artefactos sería parte de actividades económicas que, probablemente, se dieron en el sitio mismo. Este es el caso de las puntas de proyectil de obsidiana, las cuales destacan dentro de todo el material lítico, especialmente en los niveles ocupacionales Pukara (Figura 16).

\section{Fechados radiocarbónicos obtenidos en la Unidad 04}

Los fechados obtenidos están asociados con la excavación de la Unidad 04. Se extrajeron tres

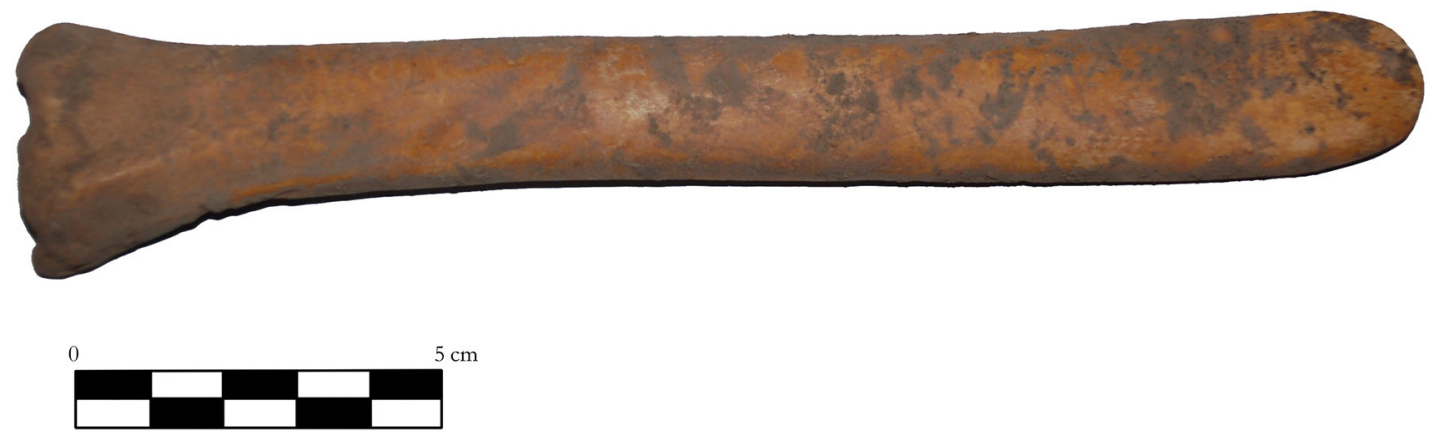

Figura 14. Artefacto para tejer (wichuña) registrado en el Locus 161, Unidad 04. Hecho probablemente de un metatarsiano o metacarpiano de camélido.

Knitting artifact (wichuña) found in Locus 161, Unit 04. It was probably, made with a camelid metatarsal or metacarpal. 


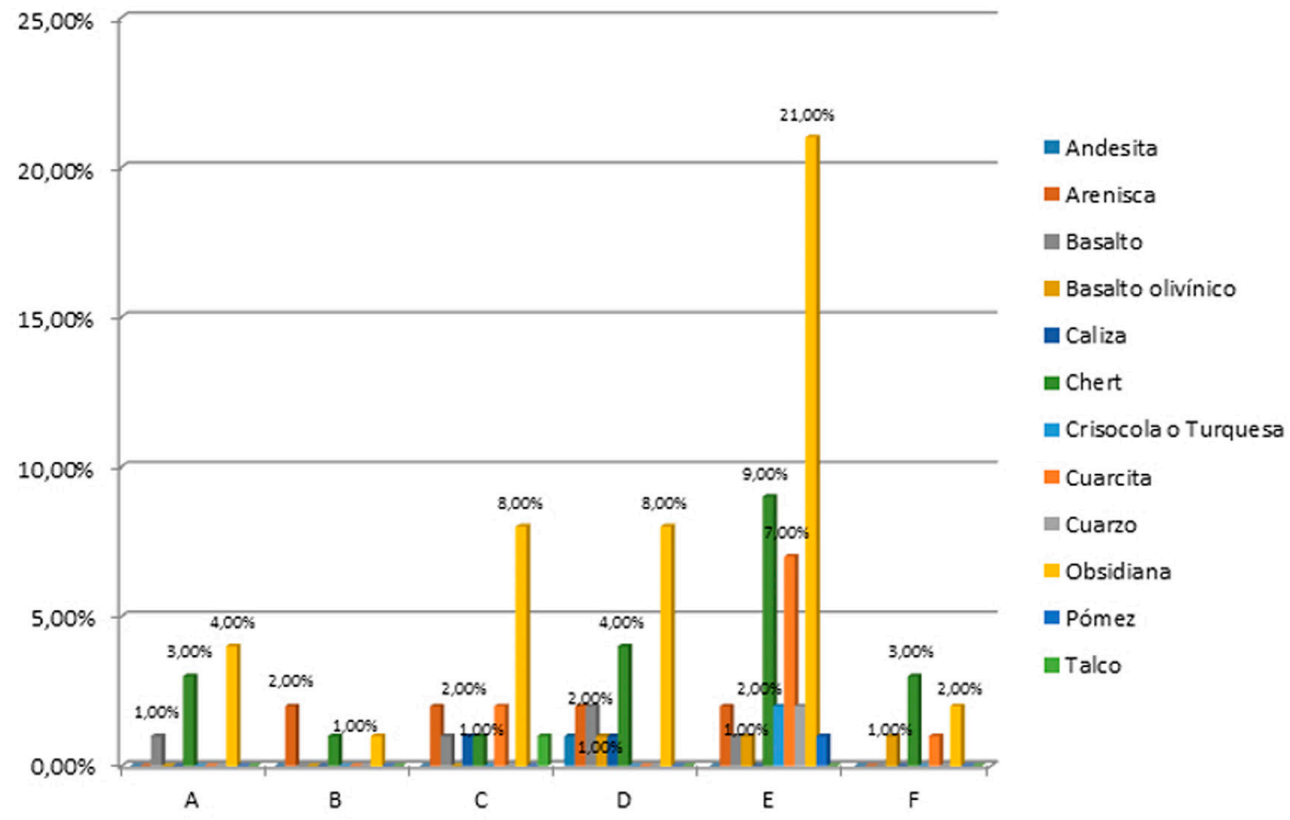

La muestra comprende 100 artefactos líticos.

Figura 15. Distribución porcentual de los artefactos líticos en las capas de la Unidad 04, por materia prima utilizada. Percentages distribution of lithic artifacts in strata of Unit 04, according to utilized raw material.

muestras de esta unidad. Dos de ellas (UCIAMS 137886 y UCIAMS 137887) pertenecen al locus 157 que está relacionado con las primeras fases de construcción del edificio vinculado, a su vez, con cerámica Pukara. Se trata del edificio rectangular hecho con base de piedras talladas localizado en la cima de la plataforma principal del sitio (Figura 7). Los fechados revelan que el edificio comenzó a ser construido en el siglo I de nuestra era (Tabla 3 ).

\section{Interpretación de los Datos Obtenidos en Chaupisawakasi}

Según las evidencias obtenidas, la plataforma principal de Chaupisawakasi fue levantada inicialmente sobre un terreno natural relativamente llano en la orilla derecha o sur del río San José y a la sombra de un promontorio rocoso bastante visible desde la pampa. Sobre dicha superficie se

Tabla 3. Fechados radiocarbónicos de muestras obtenidas durante la excavación de la Unidad 04 en el sitio de Chaupisawakasi. Radiocarbon dates of samples obtained during excavation on Unit 04 in the Chaupisawakasi site.

\begin{tabular}{|c|c|c|c|c|}
\hline Código de Laboratorio & $\begin{array}{l}\text { Código de } \\
\text { muestra }\end{array}$ & Contexto & $\begin{array}{l}\text { Edad }{ }^{14} \mathrm{C} \\
\text { (años a.p.) }\end{array}$ & $\begin{array}{l}\text { Edad }{ }^{14} \mathrm{C} \text { calibrada } \\
(\text { años Cal a.C./d.C. })^{1}\end{array}$ \\
\hline UCIAMS-137883 & $\mathrm{T}-1135$ & Locus 161 & $2070 \pm 20$ & $70 \mathrm{cal}$ a.C. $-25 \mathrm{cal}$ d.C. \\
\hline UCIAMS-137886 & T-1138 & Locus 157 & $2100 \pm 20$ & $\begin{array}{c}140-45 \text { cal a.C. }(0.92) \\
10 \text { cal a.C. }-15 \text { cal d.C. }(0.08)\end{array}$ \\
\hline UCIAMS-137887 & $\mathrm{T}-1139$ & Locus 157 & $1935 \pm 20$ & $\begin{array}{l}55-160 \text { cal d.C. }(0.87) \\
180-205 \text { cal d.C. }(0.13)\end{array}$ \\
\hline
\end{tabular}

${ }^{1}$ La calibración de la edad por carbono 14 para cada medición utilizó protocolos CALIB 7.0, empleando el conjunto de datos SHcal13 (Southern Hemisphere Calibration). Los valores del intervalo único con rango de calibración $2 \sigma$ están expresados por intercepciones que representan $\geq 0,95$ del área relativa bajo la distribución de probabilidad. Si el área relativa es $\geq 0,1$, aquel valor está entre paréntesis. En los casos de múltiples intercepciones, los rangos $2 \sigma$ con áreas relativas bajo la distribución de probabilidad de $\geq 0,05$ se anotan entre paréntesis para las separaciones de intercepción de $\geq 20$ años. Los rangos de edad se han redondeado al incremento de 5 años más próximo. 

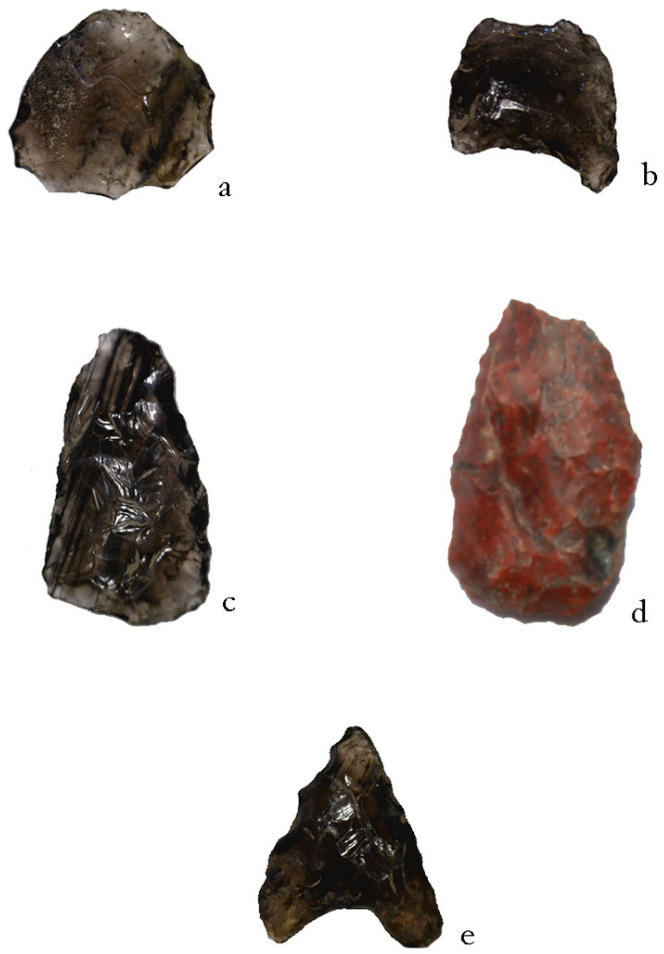

0

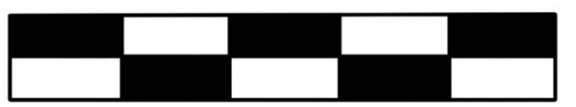

Figura 16. Puntas y preformas líticas.

Lithic arrow points and preforms.

depositaron una serie de rellenos que incluyeron material cerámico, óseo y lítico, los que permitieron incrementar el volumen y la altura de la plataforma. Posiblemente existió una ocupación inicial relacionada con el estilo cerámico Qaluyu. Será a partir del $2^{\text {do }}$ nivel ocupacional cuando se comienza a evidenciar la presencia de material relacionado con Pukara, aunque el estilo cerámico Qaluyu se siguió utilizando.

Para contener los rellenos que comenzaron a dar volumen a la plataforma se colocaron muros con grandes bloques de piedra, los cuales son visibles en la parte norte de la plataforma. La única estructura arquitectónica que hemos podido evidenciar mediante nuestras excavaciones es la que se encuentra en la parte superior del edificio comenzada a construir durante el $2^{\text {do }}$ nivel ocupacional, pero que siguió en uso hasta el $4^{\text {to }}$ nivel ocupacional. Las acumulaciones de estos niveles arqueológicos estuvieron asociadas a fragmentos de cerámica Pukara Polícromo, Qaluyu y otros restos de actividad humana. Toda esta acumulación de capas alcanzó, por lo menos, unos $2 \mathrm{~m}$ de altura.

El edificio construido durante el $2^{\text {do }}$ nivel ocupacional estaba constituido por varios recintos rectangulares alrededor de una plaza cuadrangular. Esto se evidenció en nuestras excavaciones a partir de una serie de bloques líticos unidos con argamasa de barro y que estaban orientados en sentido oesteeste (Figura 6). Sobre estas bases hechas con bloques líticos se habrían levantado muros de piedra y barro que en la actualidad han desaparecido. Dicha técnica constructiva es típica de edificios Pukara (Kidder 194; Klarich 2009; Mujica 1991; Stanish 2003; Tantaleán y Leyva 2011).

El material arqueológico asociado con este edificio se trata principalmente de una superposición de capas que contienen cerámica, entre las que resaltan las del estilo Pukara Polícromo, restos de consumo de camélidos, artefactos de hueso de camélido, artefactos líticos (como puntas de flecha de obsidiana), cuentas de minerales y hueso, fragmentos de conchas marinas y hasta un fragmento de tenaza de camarón, entre otros. Todo este material asociado a la estructura principal, y más tardía, de la plataforma, indicaría que este edificio sería el espacio de reunión y/o residencia de un pequeño grupo de personas que tenían acceso a una gran diversidad, cantidad y calidad de objetos diferenciados a los de otros sectores del sitio. Dichos sectores con arquitectura de barro y piedras se ubicaban a unos metros al este de la plataforma principal y son evidentes debido a la erosión del río (Figura 5).

De esta manera, se ha reconocido que la plataforma principal del sitio de Chaupisawakasi fue construida principalmente cuando el estilo cerámico Pukara Polícromo estaba circulando o produciéndose en el área. Las evidencias demuestran que el edificio principal de Chaupisawakasi fue construido y ocupado por grupos humanos que utilizaron y consumieron vasijas de cerámica Pukara Polícromo, un estilo más bien escaso en los sitios del valle según nuestras prospecciones superficiales (Tantaleán 2010a, 2010b; Tantaleán y Zapata Benites 2014). Adicionalmente, los fechados absolutos evidencian que tal edificio fue construido en el siglo I a.C.

Asimismo, los depósitos arqueológicos asociados con la construcción de la plataforma 
están relacionados con artefactos que se pueden relacionar con grupos sociales Pukara. Muchos de ellos son "bienes de prestigio", los cuales deben haber llegado como parte de la cultura material de los habitantes y usuarios de este edificio. Es de destacar el consumo de alimentos de alto valor nutritivo, en especial los camélidos y otras especies exóticas, incluso procedentes de valles más bajos y cálidos.

\section{Discusión}

Los análisis de los materiales arqueológicos en el sitio de Chaupisawakasi y su ubicación cronológica representan una fuente importante de información respecto de la ocupación humana de esta área altiplánica. Sobre todo, porque no poseíamos información arqueológica contextual de sitios formativos del valle del Quilcamayo-Tintiri e incluso de otros sitios contemporáneos de la cuenca del río Azángaro. Más importante aún es su relación directa con el estilo cerámico Pukara, indicador de un grupo social que fue innovador en muchos aspectos tecnológicos, económicos, políticos e ideológicos con relación a las sociedades precedentes e, incluso, generó actividades que nunca más fueron realizadas a lo largo de la historia del valle. Por ejemplo, después de la ocupación Pukara del valle del Quilcamayo-Tintiri nunca más se realizaron la construcción de plataformas con arquitectura en sus cimas, la producción de litoescultura, la producción y uso de cerámica con decoraciones polícromas e incisas y temas iconográficos complejos y la vinculación de los sitios con la agricultura extensiva en qochas. Los análisis realizados al material cerámico, lítico y zoológico recuperado en Chaupisawakasi nos han permitido reconocer y comprender importantes prácticas sociales realizadas en este sitio.

Integrando al sitio de Chaupisawakasi dentro del panorama de todo el valle del Quilcamayo-Tintiri tiene sentido que este se ubicara en un punto de control y manejo de la producción y productores de las qochas en esta zona crítica para la agricultura. Este control y manejo de la producción se hace más evidente si observamos que los principales sitios asociados con el estilo Pukara en el valle se encuentran emplazados en las confluencias de valles y quebradas y, en este caso, en la parte norte de la concentración de qochas. En ese sentido, la ubicación del sitio Pukara de Pancañe en el otro extremo de este eje norte-sur resulta relevante para comprender el control de la producción agrícola de esta parte del valle.

Existen dos escenarios posibles para explicar la generación de dichos sitios monumentales asociados con la cultura material Pukara en el valle del Quilcamayo-Tintiri: (1) existieron grupos sociales del valle del Quilcamayo-Tintiri que generaron arquitectura monumental y adquirieron cerámica y otros bienes de prestigio de sitios Pukara y (2) el valle fue colonizado por miembros del grupo social Pukara quienes reprodujeron su arquitectura y cultura material en esta área, integrándola dentro de las redes de poder económico y político Pukara.

En el caso del primer escenario, hasta el momento ningún dato de nuestra investigación indica la existencia de un grupo humano local que se haya empoderado política y económicamente en el valle del Quilcamayo-Tintiri antes o durante la aparición del fenómeno Pukara. Esto quiere decir que ni la cerámica, ni la arquitectura apuntan a un patrón distintivo y diferente al reconocido para la élite Pukara en esta región de la cuenca norte del Titicaca. Según nuestras prospecciones en el valle, los sitios más grandes aumentaron de tamaño y volumen solamente asociados con la aparición de cerámica y litoescultura de filiación Pukara. Nuestras excavaciones y recolecciones en el sitio de Chaupisawakasi así lo corroboran.

El segundo escenario resulta más plausible. Existe evidencia de una colonización discreta del valle enfocada en puntos estratégicos relacionados con el control de espacios productivos y rutas regionales. En especial, hasta la actualidad es evidente el potencial productivo mediante el cultivo de las qochas en la zona irrigada principalmente por los ríos Quilcamayo y Tintiri. De hecho, los principales sitios relacionados con arquitectura y cerámica Pukara están relacionados con esos ríos, canales y qochas (Tantaleán 2010a). Asimismo, el mismo valle es una ruta importante desde donde alcanzar la ceja de selva hasta la actualidad y nuestro registro indica que lo mismo ocurrió cuando apareció la cerámica Pukara en el valle (Tantaleán 2010a, 2010b; Tantaleán y Zapata Benites 2014). Por otra parte, la arquitectura de Chaupisawakasi y los otros sitios contemporáneos es bastante similar a la del sitio principal de Pukara, especialmente en la conformación de plataformas con volúmenes logrados con barro y piedra trabajada, que incluyen plazas orientadas cardinalmente y litoescultura con iconos Pukara. Si bien en el sitio de Chaupisawakasi 
no se han hallado estelas líticas clásicas Pukara, estas sí existen en otros sitios del valle como Cancha Cancha-Asiruni y Callacayani (Chávez y Mohr-Chávez 1970; Stanish 2003). Como vimos, la cultura material, especialmente la cerámica que describe diseños canónicos del repertorio iconográfico Pukara se ha encontrado asociada a la plataforma principal de Chaupisawakasi. Asimismo, la cantidad y calidad de material abunda con relación a los contextos arqueológicos y la misma arquitectura monumental de Chaupisawakasi que asociamos con la ocupación Pukara del sitio.

De hecho, los fechados radiocarbónicos obtenidos del edificio principal de Chaupisawakasi coinciden con el periodo Pukara Clásico ubicado entre los 200 a.C. y 100 d.C. (Klarich 2009:290) durante el esplendor del sitio epónimo. Adicionalmente, los fechados atestiguan una relación de correspondencia con otros fenómenos de expansión de Pukara en la cuenca norte del Titicaca, específicamente con la expansión de Pukara hacia el este, identificada en el sitio de Taraco (Levine 2013; Stanish y Levine 2011). Según estos investigadores, dicha expansión estuvo relacionada con un posible acto de saqueo e incendio de ese sitio alrededor del siglo I de nuestra era (Levine et al. 2012:142; Stanish y Levine 2011).

Tomando en cuenta solamente los casos de Taraco y Chaupisawakasi, podríamos reconocer al menos dos estrategias de control de espacios alejados de su zona nuclear utilizados por parte de la élite Pukara. Por un lado, una acción violenta como en el caso de Taraco donde existía una élite local asentada previamente a su llegada. Por otro lado, una estrategia en la que se realizó una ocupación territorial de una zona donde solamente existían comunidades agropastoriles, posiblemente con algún tipo de arquitectura corporativa. Este último parece ser el caso del valle de Quilcamayo-Tintiri $y$, en especial, lo que se evidencia en el mismo sitio de Chaupisawakasi y alrededores.

Así pues, nos encontraríamos ante dos estrategias empleadas por la élite residente en el centro principal de Pukara: una de confrontación violenta contra otras élites locales y otra de ocupación física y colonización de espacios habitados por comunidades aldeanas con poca integración política. En ese sentido, dos serían los principales objetivos de la élite Pukara en el valle de Quilcamayo-Tintiri: (1) la ampliación de sus "áreas de captación" de recursos y (2) la prolongación de sus redes económicas y políticas hacia el este en una ruta importante hacia la ceja de selva.

De este modo, cuando los grupos sociales Pukara llegaron al valle de Quilcamayo-Tintiri para colocar estratégicamente sus asentamientos, encontraron un paisaje social constituido por caseríos y aldeas autónomas dispersas por el valle que compartieron una tradición cerámica que es conocida arqueológicamente con el nombre de Qaluyu. Sin embargo, dichas comunidades habrían generado previamente una importante cantidad de infraestructura productiva (qochas y canales) y seguramente una producción ganadera de camélidos en un paisaje domesticado durante cientos de años antes de la llegada de los Pukara. No se descarta la existencia de arquitectura corporativa en sitios del valle, aunque esto deberá esperar a mayores excavaciones. Es altamente posible que los sitios grandes del valle con ocupación Pukara en su superficie estén construidos sobre montículos o plataformas generadas durante el periodo previo relacionado con Qaluyu como en otros casos de la cuenca norte del Titicaca (Plourde y Stanish 2006).

Así, la élite Pukara habría desarrollado un "arte de gobernar" (sensu Foucault 2007) generando una serie de estrategias para apropiarse de espacios nuevos con diferentes condiciones económicas, políticas e ideológicas. Para ello, la élite Pukara habría generado una economía política (sensu Earle y Spriggs 2015) en la cual se incorporaron "objetos con valor de cambio" o "bienes de prestigio", los cuales posibilitaban sus performances y fiestas presididas por las élites oficiales o asimiladas, desde las plataformas como las de Chaupisawakasi. En dichas fiestas se haría despliegue y exhibición de esos "símbolos de poder", los cuales se ajustaban a prácticas religiosas que reproducían las realizadas en el sitio principal de Pukara. Esto explicaría la similitud y origen de los artefactos de estilo cerámico Pukara hallados en Chaupisawakasi.

No obstante, la población local del valle de Quilcamayo-Tintiri también habría jugado un papel importante al re-orientar sus actividades productivas hacia las necesidades de la economía política Pukara. De tal manera, habrían seguido produciendo alimentos y artefactos, especialmente su cerámica vernácula, la cual se inscribía dentro de la tradición alfarera denominada como Qaluyu. Este es un fenómeno que se aprecia en otros sitios de la cuenca norte del Titicaca como, por ejemplo, 
Balsaspata (Tantaleán 2012) o el mismo Taraco (Levine 2012).

El desarrollo de una religión plasmada en la cultura material representaría una ideología que pudo haber sido una importante justificación a la cual se incorporó un componente sacrificial humano que se vislumbra en la reiteración del tema de degollamientos y los motivos de cabezas decapitadas (Chávez 1992). Dicho discurso se ha encontrado materializado tanto en escultura en piedra como en cerámica en sitios Pukara del valle (Tantaleán 2010a, 2010b).

En síntesis, nos encontramos ante un ejemplo arqueológico que sustentaría la existencia de un "Estado teocrático andino" (Tantaleán 2009), una forma política que se apoyaba en la religión con una cuota de violencia simbólica que actuaba como elemento vertebrador de las prácticas sociales establecidas por las elites. En dicha forma política los sacerdotes no solamente serían líderes religiosos sino también los que controlaban la economía política. Además, la fundación y/o reocupación de sitios en el valle vinculados directamente con el estilo Pukara supone la apropiación de lugares espaciales por grupos humanos vinculados directamente con Pukara, lo cual habría supuesto un grado de violencia fáctica. Chaupisawakasi y el valle del QuilcamayoTintiri habrían sido testigos de dichas estrategias político-económicas.

Sin embargo, tampoco deberíamos descartar la posibilidad que la reorganización del espacio productivo y la extensión de las redes comerciales por parte de las élites Pukara haya sido un elemento deseado por las comunidades y líderes locales del Quilcamayo-Tintiri, sobre todo porque incorporaron a su vida artefactos y materias primas que no podrían haber sido alcanzadas por sus propios medios. Además, los habría incorporado a un poderoso culto religioso que llevaba tiempo atrayendo personas al sitio de Pukara Al final, la comprensión de la ocupación Pukara del valle del Quilcamayo-Tintiri y otros, también tendrá que incorporar la historia de las comunidades locales (una perspectiva bottom-up), las cuales establecieron relaciones con los grupos dominantes que aún necesitamos comprender en detalle.

\section{Comentarios Finales}

Las investigaciones en el sitio arqueológico de Chaupisawakasi aportan algunas evidencias empíricas para entender el proceso de uso y control del paisaje político y económico en el valle del Quilcamayo-Tintiri. Nuestra imagen de las sociedades Qaluyu y Pukara sigue estando condicionada por la poca investigación a profundidad en los sitios vinculados con dichas "culturas". Sin embargo, los trabajos sistemáticos de reconocimiento superficial nos han brindado un importante panorama de la extensión y manifestación de volúmenes y concentración de cultura material a lo largo de la cuenca norte del Titicaca. Así, podemos comenzar a hipotetizar posibles escenarios acerca de cómo se generó uno de los más tempranos fenómenos de producción de grandes concentraciones poblacionales y de arquitectura monumental. Mayores trabajos de excavación se necesitarán para comprender las sutilezas del desarrollo político y económico prehistórico de la cuenca norte del Titicaca. Sin embargo, tenemos importantes evidencias que señalan que en el periodo Formativo Superior un grupo de elite dominó desde Pukara esta parte de la cuenca del Titicaca. Chaupisawakasi es un sitio más dentro de una red mayor que parece haber integrado tempranamente esta importante área de desarrollos prístinos en los Andes Centro Sur.

Agradecimientos: Los autores agradecen a las diferentes instituciones que hicieron posible esta investigación. Gran parte de la excavación fue financiada por la Beca Andina concedida a Tantaleán por el Instituto Francés de Estudios Andinos (IFEA) en Lima. También agradecemos a Charles Stanish quien nos apoyó económicamente para la realización de nuestros trabajos de campo y análisis de los materiales. El Ministerio de Cultura del Perú otorgó los permisos necesarios para realizar las investigaciones arqueológicas. Asimismo, agradecemos a Cecilia Chávez y Edmundo de la Vega quienes hicieron disponibles los recursos materiales necesarios para nuestra investigación. También es necesario agradecer a Margarita Quispe, Bernardino Quispe y a Joel Calcina Quispe por confiar en nosotros, albergarnos y alimentarnos en su casa de Chaupi Sahuacasi. Agradecemos especialmente a todos los miembros del PIARA que ayudaron a producir los datos sobre los que está basado este artículo. Finalmente, los autores agradecen a los dos evaluadores de este artículo quienes proporcionaron valiosos comentarios que nos ayudaron a mejorar nuestro análisis y propuestas. 


\section{Referencias Citadas}

Arkush, E. 2010. Hillforts of the Ancient Andes: Colla Warfare, Society, and Landscape. University Press of Florida, Gainesville.

Burger, R., K. Mohr-Chávez y S. Chávez 2000. Through the Glass Darkly: Prehispanic Obsidian Procurement and Exchange in Southern Peru and Northern Bolivia. Journal of World Prehistory 14:267-362.

Chávez, S. 1992. The Conventionalized Rules in Pucara Pottery Technology and Iconography: Implications of Socio-Political Development in the Northern Titicaca Basin. Tesis doctoral, Michigan State University, East Lansing.

Chávez, S. y K. Mohr-Chávez 1970. Newly Discovered Monoliths of Puno, Perú. Expedition 12(4):25-39.

Cohen, A. 2010. Ritual and Architecture in the Titicaca Basin: The Development of the Sunken Court Complex in the Formative Period. Tesis doctoral, Departamento de Antropología, University of California, Los Angeles.

Earle, T. y M. Spriggs 2015. Political Economy in Prehistory. A Marxist Approach to Pacific Sequences. Current Anthropology 56:515-544.

Flores Ochoa, J. y P. Paz 1983. La Agricultura en Lagunas del Altiplano. Nawpa Pacha 21:127-152.

Flores, L., N. Craig y M. Aldenderfer 2012. Las Qochas y su Relación con Sitios Tempranos en el Ramis, Norte de la Cuenca del Titicaca. En Arqueología de la Cuenca del Titicaca, Perú, editado por L. Flores y H. Tantaleán, pp. 225-242. IFEA, Lima.

Foucault, M. 2007. El Nacimiento de la Biopolítica. Fondo de Cultura Económica, Buenos Aires.

Kidder II, A. 1943. Some Early Sites in the Northern Titikaka Basin. Papers of the Peabody Museum of American Archaeology and Ethnology, Harvard University 27(1). Cambridge.

Klarich, E. 2005a. From the Monumental to the Mundane: Defining Early Leadership Strategies at Late Formative Pukara, Peru. Tesis doctoral, Departamento de Antropología, University of California, Santa Barbara.

Klarich, E. 2005b. ¿Quiénes Eran los Invitados? Cambios Temporales y Funcionales de los Espacios Públicos de Pukara Como Reflejo del Cambio de las Estrategias de Liderazgo Durante el Periodo Formativo Tardío. Boletín de Arqueología PUCP 9:185-206.

Klarich, E. 2009. Pukara: Investigaciones de la Temporada 2001 y un Nuevo Modelo para el Desarrollo del Sitio. En Arqueología del Área Centro Sur Andina, editado por M.S. Ziołkowski, J. Jennings, L.A. Belán Franco y A. Drusini, pp. 283-303. Centro de Estudios Precolombinos de la Universidad de Varsovia/ IFEA, Lima.

Levine, A. 2012. Competition, Cooperation, and the Emergence of Regional Centers in the Northern Lake Titicaca Basin, Peru. Tesis doctoral. Departamento de Antropología, University of California Los Angeles, Los Angeles.

Levine, A. 2013. The Use and Re-Use of Ceremonial Space at Taraco, Peru: 2012 Excavations in the San Taraco Sector. Ñawpa Pacha 33:215-226.

Levine, A., C. Chávez, A. Cohen, A. Plourde y C. Stanish 2012. El Surgimiento de la Complejidad Social en la Cuenca Norte del Titicaca. En Arqueología de la Cuenca del Titicaca, Perú, editado por L. Flores y H. Tantaleán, pp. 131-154. IFEA y Cotsen Institute, UCLA, Lima.

Mohr-Chávez, K. 1977. Marcavalle: The Ceramics from an Early Horizon Site in the Valley of Cuzco, Peru, and Implications for South Highland Socio-Economic Interaction. Tesis doctoral. Departamento de Antropología, University of Pennsylvania.

Mujica, E. 1978. Nueva Hipótesis sobre el Desarrollo Temprano del Altiplano del Titicaca y sus Áreas de Interacción. Arte y Arqueología 5-6:285-308.

Mujica, E. 1991. Pukara: Una Sociedad Compleja Temprana en la Cuenca Norte del Titicaca. En Los Incas y el Antiguo Perú. 3000 Años de Historia, editado por E. Mujica, pp. 272-297. Sociedad Estatal Quinto Centenario, Madrid.

Mujica, E. y J. Wheeler 1981. Producción y Recursos Ganaderos Prehispánicos en la Cuenca del Titicaca. Centro de Investigación y Restauración de Bienes Monumentales, Instituto Nacional de Cultura, Lima.

ONERN 1965. Programa de Inventario y Evaluación de los Recursos Naturales del Departamento de Puno. Sector de Prioridad 1. Vol. 1. Oficina Nacional de Evaluación de Recursos Naturales, Oficina de la Presidencia de la República, Lima.

Plourde, A. 2006. Prestige Goods and their Role in the Evolution of Social Ranking: A Costly Signaling Model with Data from the Formative Period of the Northern Lake Titicaca Basin, Peru. Tesis doctoral. Departamento de Antropología. University of California, Los Angeles, Los Angeles.

Plourde, A. y C. Stanish 2006. The Emergence of Complex Society in the Titicaca Basin: The View from the North. En Andean Archaeology III. North and South, editado por W. Isbell y H. Silverman, pp. 237-257. Springer, New York.

Rowe, J. 1963. Urban Settlements in Ancient Perú. Ñawpa Pacha, 1(1): 1-27.

Stanish, C. 2003. Ancient Titicaca. The Evolution of Social Power in the Titicaca Basin of Peru and Bolivia. University of California Press, Berkeley y Los Angeles.

Stanish, C. y A. Levine 2011. War and Early State Formation in the Northern Titicaca Basin, Peru. Proceedings of the National Academy of Sciences 108:13901-13906.

Stanish, C., A. Cohen, E. de la Vega, E. Arkush, C. Chávez, A. Plourde y C. Schultze 2005. Archaeological Reconnaissance in the Northern Titicaca Basin. En Advances in Titicaca Basin Archaeology-1, editado por C. Stanish, A. Cohen y M. Aldenderfer, pp. 289-316. Cotsen Institute UCLA, Los Angeles.

Stanish, C., C. Chávez, K. Lafavre y A. Plourde 2014. The Northern Titicaca Survey. Huancané-Putina. Museum of Anthropology, University of Michigan, Ann Arbor.

Tantaleán, H. 2009. Chavín de Huántar y la Definición Arqueológica de un Estado Teocrático Andino. Boletín de Antropología Americana 45:99-168.

Tantaleán, H. 2010a. Ideología y Realidad en las Primeras Sociedades Sedentarias (1400 ANE-350 DNE) de la Cuenca Norte del Titicaca, Perú. British Archaeological Reports, Oxford. 
Tantaleán, H. 2010b. Del Espacio Inclusivo al Espacio Exclusivo: Las Primeras Sociedades Sedentarias (1400 ANE-400 DNE) del Valle del Quilcamayo-Tintiri, Azángaro, Puno. En Arqueología en el Perú. Nuevos Aportes para el Estudio de las Sociedades Andinas Prehispánicas, editado por R. Romero y T. Pavel, pp. 39-69. Universidad Federico Villarreal, Lima.

Tantaleán, H. 2012. Archaeological Excavation at Balsaspata, Ayaviri. En Advances in Titicaca Basin Archaeology-III, editado por A. Vranich, E. Klarich y C. Stanish, pp. 49-75. Memoirs of the Museum of Anthropology, University of Michigan, Ann Arbor.

Tantaleán, H. y M. Leyva 2011. De la Huanca a la Estela: La Formación de los Asentamientos Permanentes Tempranos (1400 ANE-350 DNE) de la Cuenca Norte del Titicaca. Bulletin de l'Institut Français d'Études Andines 40:259-287.
Tantaleán, H., M. Zegarra, A. Gonzáles y C. Zapata Benites 2012. Qaluyu y Pukara: Una Perspectiva Desde el Valle del QuilcamayoTintiri, Azángaro. En Arqueología de la Cuenca del Titicaca, Perú, editado por L. Flores y H. Tantaleán, pp. 155-193. IFEA, Lima.

Tantaleán, H. y C. Zapata Benites 2014. Chaupisawakasi y la Formación del Estado Pukara (400 a.C.-350 d.C.) en la Cuenca Norte del Titicaca. British Archaeological Reports. British Archaeological Reports, Internacional Series 2687, Oxford.

Valcárcel, L.E. 1925. Informe sobre la Exploración Arqueológica de Pukara. Revista Universitaria 48:14-21.

Warwick, M. 2012. In the Shadow of the Peñon: A Zooarchaeological Study of Formative Diet, Economy, and Sociopolitics in the Río Pukara Valley, Peru. Tesis doctoral, Departamento de Antropología, University of Wisconsin, Milwaukee. 
